\title{
Advances and Challenges at the National Hurricane Center
}

\author{
Edward N. Rappaport, James L. Franklin, Lixion A. Avila, Stephen R. BAig, ${ }^{*}$ John L. Beven II, \\ Eric S. Blake, Christopher A. Burr, JiAnn-Gwo JiIng, Christopher A. JuCKins, Richard \\ D. KnABB, Christopher W. LANDSEA, Michelle Mainelli, ${ }^{+}$MAX MAYField, ${ }^{\#}$ Colin J. McAdie, \\ Richard J. PAsch, Christopher Sisko, Stacy R. STEwArt, AND Ahsha N. TribBle@
}

NOAA/National Weather Service/National Hurricane Center, Miami, Florida

(Manuscript received 9 February 2008, in final form 1 October 2008)

\begin{abstract}
The National Hurricane Center issues analyses, forecasts, and warnings over large parts of the North Atlantic and Pacific Oceans, and in support of many nearby countries. Advances in observational capabilities, operational numerical weather prediction, and forecaster tools and support systems over the past 15-20 yr have enabled the center to make more accurate forecasts, extend forecast lead times, and provide new products and services. Important limitations, however, persist. This paper discusses the current workings and state of the nation's hurricane warning program, and highlights recent improvements and the enabling science and technology. It concludes with a look ahead at opportunities to address challenges.
\end{abstract}

\section{Introduction}

The National Hurricane Center-Past, Present and Future (Sheets 1990) chronicled the U.S. government civilian hurricane forecast and warning service from its beginnings in the nineteenth century through the 1980s. It also described the responsibilities, and the tools and processes applied at the end of that period at the National Hurricane Center (NHC; see Table 1 for a list of acronyms and their expansions used in this paper).

Sheets's 1990 review occurred near the end of a $\sim 25$ yr period of relatively low hurricane activity and impact in the United States after Hurricane Camille (1969). Not coincidentally, storm surge, this country's greatest tropical cyclone threat historically, caused few casualties during that period. Like other NHC directors, Sheets made clear, however, that additional hurricane disasters were imminent and would be exacerbated by

\footnotetext{
*Retired.

${ }^{+}$Current affiliation: National Centers for Environmental Prediction Central Operations, Camp Springs, Maryland. \#Current affiliation: WPLG-TV, Miami, Florida. @Current affiliation: National Weather Service/Climate Service Division, Silver Spring, Maryland.
}

Corresponding author address: Edward N. Rappaport, National Hurricane Center, 11691 SW 17th St., Miami, FL 33165-2149. E-mail: edward.n.rappaport@noaa.gov an expected continued rapid growth of coastal populations and infrastructure.

A large increase in Atlantic basin tropical cyclone events and impacts indeed followed. The activity included the busiest season on record (2005, with 28 tropical storms ${ }^{1}$ and hurricanes), the most intense hurricane (as measured by central pressure) on record (Wilma of 2005), one of the deadliest hurricanes (Mitch of 1998), the deadliest U.S. hurricane in more than $75 \mathrm{yr}$ and the costliest ever (Katrina of 2005), and the third strongest hurricane at U.S. landfall (Andrew of 1992). This period also presented its share of critical operational challenges, including some memorable instances where forecasts fell short of goals. Examples include Andrew's acceleration toward Florida, Mitch's southward movement (Pasch et al. 2001), Wilma's unprecedented intensification (Beven et al. 2008), and Humberto's development during 2007 from a weak low into a landfalling hurricane in less than $24 \mathrm{~h}$ (Blake 2007).

Sheets's article served not only to describe the nation's hurricane program, but also to educate readers on the U.S. hurricane problem. His depiction, based on National Weather Service (NWS) storm surge

\footnotetext{
${ }^{1}$ This count includes one subtropical storm. In this paper, the term "tropical cyclone" refers to both tropical and subtropical systems of depression [ $\left.<34 \mathrm{kt}\left(17.5 \mathrm{~m} \mathrm{~s}^{-1}\right)\right]$, storm [34-63 kt (17.5$\left.\left.32.4 \mathrm{~m} \mathrm{~s}^{-1}\right)\right]$, or hurricane $\left[\geq 64 \mathrm{kt}\left(32.4 \mathrm{~m} \mathrm{~s}^{-1}\right)\right]$ intensity.
} 
TABLE 1. List of key acronyms, and their expansions, used in this paper.

\begin{tabular}{|c|c|}
\hline Acronym & Expansion \\
\hline AFFO & Announcement of Federal Funding Opportunity \\
\hline AFOS & Automation of Field Operations and Services \\
\hline AFRES & Air Force Reserve Command \\
\hline AMSR & Aqua Microwave Scanning Radiometer \\
\hline AMSU & Advanced Microwave Sounding Unit \\
\hline ASCAT & Advanced Scatterometer \\
\hline ATCF & Automated Tropical Cyclone Forecasting system \\
\hline AWC & Aviation Weather Center \\
\hline CARCAH & $\begin{array}{l}\text { Chief, Aerial Reconnaissance Coordination, } \\
\text { All Hurricanes }\end{array}$ \\
\hline CLIPER & Climatology and persistence \\
\hline DMSP & Defense Meteorological Satellite Program \\
\hline DOD & Department of Defense \\
\hline ECMWF & $\begin{array}{l}\text { European Centre for Medium-Range Weather } \\
\text { Forecasts }\end{array}$ \\
\hline EMC & Environmental Modeling Center \\
\hline FEMA & Federal Emergency Management Agency \\
\hline GEMPAK & General Meteorological Package \\
\hline GFDL & Geophysical Fluid Dynamics Laboratory \\
\hline GFS & Global Forecast System \\
\hline GIS & Geographic Information System \\
\hline G-IV & Gulfstream-IV \\
\hline GOES & $\begin{array}{l}\text { Geostationary Operational Environmental } \\
\text { Satellite }\end{array}$ \\
\hline GPRA & Government Performance and Results Act \\
\hline GPS & Global positioning system \\
\hline GUNA & $\begin{array}{l}\text { Consensus model of the GFDL Hurricane Model, } \\
\text { the U.K. Met Office Global Model, NOGAPS, } \\
\text { and the GFS (formerly known as the Aviation } \\
\text { Model) }\end{array}$ \\
\hline HFIP & Hurricane Forecast Improvement Project \\
\hline HFS & Hurricane Forecast System \\
\hline HLT & Hurricane Liaison Team \\
\hline $\mathrm{HPC}$ & Hydrometeorological Prediction Center \\
\hline HRD & Hurricane Research Division \\
\hline HSU & Hurricane Specialists Unit \\
\hline HURDAT & Hurricane Database \\
\hline HWRF & Hurricane Weather Research and Forecast \\
\hline IT & Information technology \\
\hline JHT & Joint Hurricane Testbed \\
\hline JTWC & Joint Typhoon Warning Center \\
\hline Lidar & Light distance and ranging \\
\hline MDL & Meteorological Development Laboratory \\
\hline MEOW & Maximum envelope of water \\
\hline Meteosat & Meteorological Satellite \\
\hline MOM & Maximum of maxima \\
\hline NAVTEX & Navigation Telex Radio \\
\hline N-AWIPS & $\begin{array}{l}\text { NCEP Advanced Weather Interactive Processing } \\
\text { System }\end{array}$ \\
\hline NCAR & National Center for Atmospheric Research \\
\hline NCEP & National Centers for Environmental Prediction \\
\hline $\mathrm{NCO}$ & NCEP Central Operations \\
\hline NDFD & National Digital Forecast Database \\
\hline NEXRAD & Next-Generation Radar \\
\hline NHC & National Hurricane Center \\
\hline NHOP & National Hurricane Operations Plan \\
\hline NMM & Nonhydrostatic Mesoscale Model \\
\hline NOAA & $\begin{array}{l}\text { National Oceanic and Atmospheric } \\
\text { Administration }\end{array}$ \\
\hline
\end{tabular}

TABLE 1. (Continued)

\begin{tabular}{ll}
\hline \hline Acronym & \multicolumn{1}{c}{ Expansion } \\
\hline NOGAPS & $\begin{array}{l}\text { Navy Operational Global Atmospheric Prediction } \\
\text { System }\end{array}$ \\
NPOESS & $\begin{array}{l}\text { National Polar-Orbiting Environmental } \\
\text { Satellite System } \\
\text { Naval Research Laboratory }\end{array}$ \\
NRL & National Weather Service \\
NWS & Ocean Prediction Center \\
OPC & Personal digital assistant \\
PDA & Quick Scatterometer \\
QuikSCAT & Regional Association \\
RA & Radius of maximum wind \\
RMW & Regional Specialized Meteorological Center \\
RSMC & Really Simple Syndication \\
RSS & Stepped-Frequency Microwave Radiometer \\
SFMR & Statistical Hurricane Intensity Forecast \\
SHIFOR & Statistical Hurricane Intensity Prediction Scheme \\
SHIPS & Sea, Lake, and Overland Surges from Hurricanes \\
SLOSH & Science and operations officer \\
SOO & Scanning Radar Altimeter \\
SRA & Special Sensor Microwave Imager \\
SSM/I & Tropical Analysis and Forecast Branch \\
TAFB & Tropical cyclone report \\
TCR & Techniques Development and Applications Unit \\
TDAU & Tropical Rainfall Measuring Mission \\
TRMM & Technical Support Branch \\
TSB & Tropical weather outlook \\
TWO & U.K. Met Office \\
UKMET & U.S. Weather Research Program \\
USWRP & Weather Forecast Office \\
WFO & \\
\hline &
\end{tabular}

simulations, of a hurricane putting $20+\mathrm{ft}(6+\mathrm{m})$ of water in New Orleans and environs was prescient (his Fig. 2b). Fifteen years later Katrina struck that area, directly causing about 1500 fatalities $^{2}$ and causing damage estimated at $\$ 81$ billion (Beven et al. 2008). Yet, well before its arrival, some had projected the impact in that area of a strong hurricane would be much worse, with fatalities reaching 60000 (Cooper and Block 2006) or even 100000 (Schleifstein and McQuaid 2002).

By any measure the losses from Katrina are tragic. Put in the context of the above projections, however, the relatively low loss of life is noteworthy. Such a result did not occur by chance, but rather reflects significant cumulative advances in hurricane forecasting, communication methods, and preparedness processes made by $\mathrm{NHC}$ and/or its public and private partners-in many aspects collaboratively. Willoughby et al. (2007) estimated that such advances "prevented $66-90 \%$ of the

\footnotetext{
${ }^{2}$ NHC's estimate of 1500 deaths directly attributed to Katrina (e.g., Beven et al. 2008) may need to be revised downward to less than 1000 based on a more detailed analysis of the impact on Louisiana (E. Boyd 2007, personal communication).
} 
hurricane-related deaths in the United States that would have resulted from techniques used in the 1950s....' These efforts by NHC and others produced accurate and consistent forecasts for Katrina in the 2-3 days before its Gulf landfall-forecasts that were said to have saved many lives. United States Senator Jim DeMint of South Carolina, chairman of the Commerce Committee's Disaster Prediction and Prevention Subcommittee, stated "These early and accurate forecasts [of Katrina] saved countless lives along the Gulf Coast.... We owe a debt of gratitude to Director Mayfield and his team of scientists for their hard work." During the 2004 hurricane season, NHC was recognized by the first visit to the center by a U.S. president, and the president made two subsequent visits to NHC in 2005 and 2006.

The center's focus on public service and safety was formalized in its mission and vision statements developed in 2001. NHC's mission is

To save lives, mitigate property loss, and improve economic efficiency by issuing the best watches, warnings, forecasts, and analyses of hazardous tropical weather, and by increasing understanding of these hazards.

\section{NHC's vision is}

To be America's calm, clear, and trusted voice in the eye of the storm, and, with our partners, enable communities to be safe from tropical weather threats.

While gains clearly have been made, the losses in Katrina and in other storms, the looming threat of additional tropical cyclone-induced loss of life, and the remaining significant limitations in tropical cyclone forecast accuracy show that much work remains to be done to fully address the goals set by NHC in its mission and vision statements. This paper discusses the current workings and state of the nation's hurricane warning program, highlighting improvements that have occurred since Sheets's review, and concludes with a look at opportunities to address challenges that lie ahead.

\section{NHC organizational structure and forecast operations}

When it became part of the National Centers for Environmental Prediction (NCEP) in 1995, NHC became known then alternately as the Tropical Prediction Center. NHC moved that year from its offices in Coral Gables, Florida, to its current facility on the campus of Florida International University in Miami, Florida. The $25000 \mathrm{ft}^{2}$ building houses both NHC and the National Weather Service's Miami Weather Forecast Office (WFO). Its design team included engineer Herb Saffir, an originator of the Saffir-Simpson hurricane scale. The facility has many enhanced structural and redundant fea- tures allowing forecast operations to continue through most local weather and other emergencies.

NHC's \$6.4M (fiscal year 2008) budget supports 46 federal government employees and associated infrastructure. Other components of the federal government bear the costs for weather observations, computer modeling, most tropical weather research, etc. used by NHC.

NHC comprises three operational workgroups, the Hurricane Specialists Unit (HSU), the Tropical Analysis and Forecast Branch (TAFB), and the Technical Support Branch (TSB). Their activities are described below. NHC also has a small administrative staff led by its director. Following Robert Sheets (1987-95) in that position were Robert Burpee (1995-97), Jerry Jarrell (19982000), Max Mayfield (2000-2007), Bill Proenza (2007), and Bill Read (2008-present). About a dozen employees from other federal agencies collaborate on site with NHC staff.

\section{a. Hurricane Specialists Unit (HSU)}

The HSU has a full-time focus on hurricanes, with its members having a wide array of responsibilities throughout the calendar year. During hurricane season, (15 May-30 November in the eastern North Pacific and 1 June-30 November in the Atlantic basin) they develop, coordinate, and issue analyses, forecasts, and coastal tropical cyclone watches and warnings in text and graphical formats. They also provide briefings on active tropical cyclones to emergency managers and the media, and write poststorm tropical cyclone reports on each system shortly after the event. Their products are governed by NWS directives, instructions, and manuals (NWS 2007), the National Hurricane Operations Plan (NHOP) for U.S. Federal Agencies (OFCM 2007), and the World Meteorological Organization (WMO) Regional Association (RA) IV Hurricane Operational Plan (WMO 2006).

NHC is a WMO Regional Specialized Meteorological Center (RSMC) with responsibility for tropical cyclone forecasts throughout the North Atlantic and eastern North Pacific basins bounded by the thickest red lines in Fig. 1. The WMO moved the eastern boundary of this area eastward from $35^{\circ} \mathrm{W}$ to the coasts of Africa and western Europe in 2005, expanding NHC's forecast responsibilities to support more than 30 countries in the area, and the global marine interests over the vast waters shown. NHC and the countries in this area continue to enjoy a decades-long close working relationship where observational data, forecasts, training, and ideas have been shared. Most countries in NHC's areas of responsibility issue their own tropical storm and hurricane watches and warnings, usually based on forecasts and recommendations from NHC. 


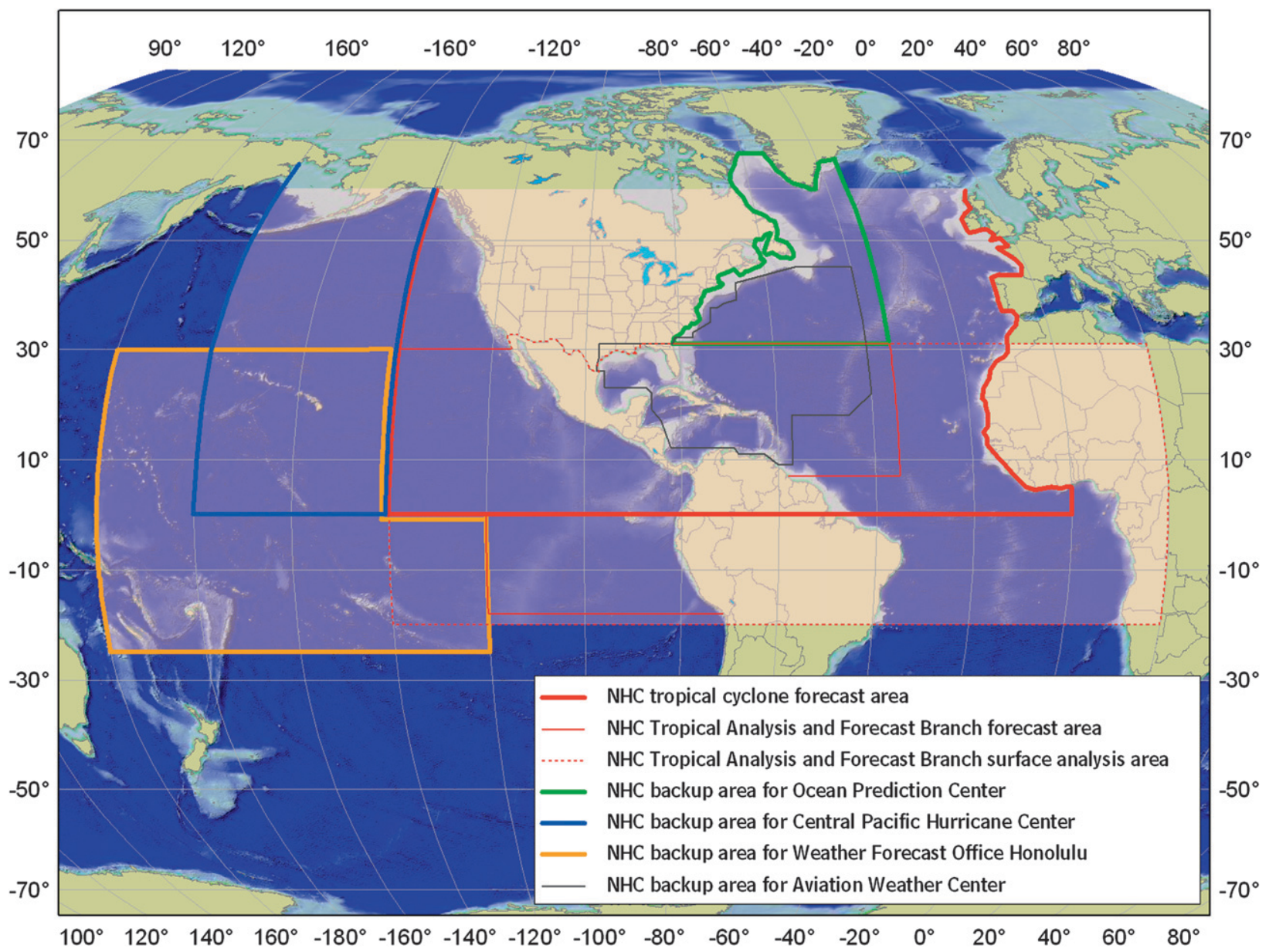

FIG. 1. NHC areas of analysis and/or forecast responsibility.

In addition to its forecast responsibilities, $\mathrm{NHC}$ issues coastal tropical storm and hurricane watches ${ }^{3}$ and warnings ${ }^{4}$ for U.S. areas in Fig. 1, including Puerto Rico and the U.S. Virgin Islands, in collaboration with WFOs. The WFOs issue tropical storm and hurricane watches and warnings for inland U.S. locations.

For all active tropical cyclones in the Atlantic and eastern North Pacific basins, the hurricane specialists at the NHC issue a suite of forecast products every $6 \mathrm{~h}$ that contain projections valid $12,24,36,48,72,96$, and $120 \mathrm{~h}$ after the forecast's initial synoptic time $(0000,0600$, 1200 , or 1800 UTC). This nominal initial time represents the beginning of the forecast process, as the actual advisory products are not released until $3 \mathrm{~h}$ after the nominal initial time. The forecasts include the cyclone's

\footnotetext{
${ }^{3}$ A hurricane watch means hurricane conditions are possible somewhere within the watch area during the next $36 \mathrm{~h}$.

${ }^{4}$ A hurricane warning means hurricane conditions are expected somewhere within the warning area during the next $24 \mathrm{~h}$.
}

center position (location of the circulation center in latitude and longitude) to the nearest $0.1^{\circ}$ (generally $0.5^{\circ}$ at extended forecast periods) and maximum surface wind speed (maximum sustained 1-min-average wind speed at $10-\mathrm{m}$ altitude) to the nearest $5 \mathrm{kt}\left(2.6 \mathrm{~m} \mathrm{~s}^{-1}\right)$. Five-day forecasts became operational in 2003 , prior to which 3-day forecasts had been issued since 1964. The size of a tropical cyclone is conveyed via wind radii that represent the maximum horizontal extent in each of four quadrants (northeast, southeast, etc.) of a particular sustained wind speed from the circulation center. Wind radii for 34 and $50 \mathrm{kt}$ are forecast through $72 \mathrm{~h}$ and 64-kt radii are forecast through $36 \mathrm{~h}$. Radii of $12-\mathrm{ft}$ $(3.7 \mathrm{~m})$ seas are included for the advisory time.

NHC's advisory suite comprises several text and graphical products. The primary text products are the tropical cyclone public advisory, forecast/advisory, and discussion. The public advisory is a plain-language report on current and short-term forecast characteristics, along with coastal hurricane and tropical storm watch and 
warning information. The forecast/advisory provides quantitative forecast information about the cyclone's location, intensity, and size. The discussion conveys NHC's reasoning behind its analysis and forecast, information about the (un)certainty in the forecast, and possible alternate forecast solutions. In 2006 the wind speed probability text product (section $7 \mathrm{~b}$ ) was introduced into the advisory suite. This product conveys the chances of sustained winds of tropical storm and hurricane force at specific locations through $120 \mathrm{~h}$, by considering the combined uncertainties in the forecast track, intensity, and size (Gross et al. 2004). This wind speed probability text product replaced the strike probability product (Sheets 1985) that had been issued only for Atlantic basin tropical cyclones (and only out to $72 \mathrm{~h}$ ).

Other text products can be issued between the regular 6-hourly advisory packages. Intermediate public advisories are issued when watches and/or warnings are in effect, at 2-h intervals when land-based radar can provide reliable center location fixes, and at 3-h intervals otherwise. In addition, tropical cyclone position estimates are issued in between two-hourly intermediate public advisories. This means NHC products give the cyclone's estimated location hourly when the threat is imminent. A "special advisory" package comprising the standard suite of products can be issued at any time to convey a significant change to the previous forecast before the next regularly scheduled issuance. The tropical cyclone update is a short text product used to advise of significant changes in a cyclone or to advise of changes to watches or warnings.

NHC's tropical cyclone track and watches-warnings graphic includes a shaded area around the forecast track to convey uncertainty in that forecast based on official forecast error statistics for the preceding 5-yr period. In addition to the wind speed probability text product, the companion graphical wind speed probability products became operational in 2006. A maximum wind speed probability table is also produced to convey uncertainties in the forecast intensity of the cyclone.

The HSU also issues tropical weather outlook (TWO) text products four times daily during the hurricane season in both the Atlantic and eastern North Pacific basins. These products describe tropical weather systems of significance and their potential for tropical cyclone formation during the next $48 \mathrm{~h}$. A special TWO can be used to describe formative tropical systems that have not become a tropical cyclone, especially if significant changes have occurred since the most recent TWO, and for potential tropical cyclones outside of the hurricane season.

Monthly tropical weather summaries are issued by the HSU at the end of each month of the hurricane season for both the North Atlantic and eastern North Pacific basins. These text products indicate preliminarily the formation and end dates and estimated peak intensity of each tropical cyclone occurring during the month. After the conclusion of a tropical cyclone, the hurricane specialists produce a tropical cyclone report (TCR) based on their poststorm analysis of all available data. The report includes an official "best track" chronology of storm center locations, maximum wind speeds, and minimum pressures, as well as a synoptic history, summaries and tabulations of important meteorological observations, casualty and damage statistics, and a forecast and warning critique.

NHC tropical cyclone data acquisition, public products, forecasts, and watches-warnings are coordinated with various other entities in person, via a "hurricane hotline" (discussed in section 7d), conventional telephone lines, and/or e-mail. Forecast and warning coordination with international weather services relies on conventional telephone lines and can occur in languages other than English-primarily Spanish and French. The coordination process facilitates a division of responsibility in which NHC products provide "the big picture" while WFOs and WMO international meteorological services typically focus on complementary details on local conditions.

NHC also coordinates with the NCEP Hydrometeorological Prediction Center (HPC) and the Department of Defense regarding potential locations of tropical cyclones in the medium range (days 3-7) from 1 June to 30 November. Hurricane specialists request aircraft reconnaissance missions through the Chief, Aerial Reconnaissance Coordination, All Hurricanes (CARCAH) unit at NHC. Hurricane specialists interact closely with CARCAH during missions to maximize mission effectiveness. Additional discussion of the aircraft program is provided in sections $4 \mathrm{c}$ and $4 \mathrm{e}$.

The HSU issues an average of around 700 full advisory packages per year. The unit grew from 6 to 10 members prior to the 2006 hurricane season to better handle the increased numbers of operational products and services; expanded forecast horizon; additional observational data, model guidance, and storms; and new applied research activities. The original six positions are now referred to as senior hurricane specialists, who currently average about $15 \mathrm{yr}$ of government tropical cyclone forecasting experience. NHC is also adding an HSU branch chief in 2009. Even this increased level of staffing within the HSU, however, is insufficient during periods of heightened activity. During the peak months of the Atlantic season (August-October), TAFB and TSB staff assist the HSU in meeting operational requirements as "hurricane support meteorologists." They can help 
prepare tropical cyclone advisories, enter and analyze operational data, speak to media and emergency managers, and write TCRs.

Hurricane specialists remain busy outside the hurricane season. Their responsibilities include the occasional off-season tropical cyclone (e.g., Epsilon and Zeta in 2005-06); participating in several national and international conferences; training emergency managers, the media, and other meteorologists; conducting public outreach and preparedness programs; writing seasonal summary articles (e.g., Beven et al. 2008); and participating in applied research projects. One such project is the United States Weather Research Program's (USWRP) Joint Hurricane Testbed (JHT; see section $6 \mathrm{c}$ ). NHC also helps the Climate Prediction Center prepare the NOAA annual seasonal hurricane forecast (R. W. Higgins et al. 2008, personal communication).

\section{b. Tropical Analysis and Forecast Branch (TAFB)}

The TAFB is composed of a branch chief, five lead forecasters, 10 forecasters, and two meteorologist interns. They issue operational marine and tropical products 24 hours per day year-round within a 14 million $(\mathrm{n} \mathrm{mi})^{2}$ area of the tropical and subtropical North Atlantic, Caribbean Sea, Gulf of Mexico, and parts of the tropical and subtropical eastern North and South Pacific (Fig. 1). The eastern South Pacific responsibility was added in 1991.

The branch staffs three operational desks: Atlantic marine, Pacific marine-tropical cyclone classifications, and Atlantic-Pacific analysis. A fourth desk is staffed during the peak of the hurricane season in the daytime to meet an increased workload. TAFB's customers include operators of commercial fishing vessels, yachts, cruise ships, and vessels making transoceanic voyages as well as the meteorological services of coastal nations. TAFB issues the majority of NHC products, about 100 per day, split almost evenly between text and graphical formats. Methods for communicating products include the Internet, radiofacsimiles (out of the New Orleans; Point Reyes, California; and Honolulu, Hawaii, transmitter sites), synthesized voice, Navigation Telex Radio (NAVTEX), and International Mobile Satellite Organization's SafetyNET.

Graphical products include surface analyses, windwave (e.g., Fig. 2) and surface forecast charts out to 72 h, sea-state analyses, tropical cyclone danger areas, and peak wave period-peak swell direction charts to $72 \mathrm{~h}$. A high-wind and associated seas chart replaces the tropical cyclone danger area graphic outside of the hurricane season. TAFB has close operational ties with HPC, the Ocean Prediction Center (OPC), and WFO Honolulu, and collaborates with them to produce the surface analysis.
Text products include high seas forecasts to $48 \mathrm{~h}$, offshore waters forecasts to $120 \mathrm{~h}$ sent via marine and tropical weather discussions, and a pan-American present weather-temperature-precipitation table. Several of these products were added near the time when the TAFB tropical aviation program was transferred to the NCEP Aviation Weather Center (AWC) in 2000.

The branch produces for the HSU tropical cyclone position and intensity estimates based on the Dvorak (1984) geostationary satellite analysis technique, and similar estimates for subtropical systems (Hebert and Poteat 1975). In 2004, TAFB began making tropical cyclone center position estimates using passive microwave satellite imagery. TAFB generates precipitation estimates for tropical systems within 36-48 h of landfall, mainly for forecasters and emergency managers in RAIV countries.

TAFB writes papers on marine and tropical weather topics for technical conferences, and an article highlighting high-wind and sea events three times per year for the Mariner's Weather Log. It also works on JHT projects and has an outreach component dedicated to marine-ocean and weather issues.

\section{c. Technical Support Branch (TSB)}

The TSB oversees NHC's local information technology (IT) needs, providing ( $24 \mathrm{~h}) \mathrm{day}^{-1}$ support for operational equipment and data flow. It also develops and implements new tropical cyclone and tropical weather analysis and forecast techniques, updates storm surge basin databases and generates real-time storm surge forecasts, and organizes and conducts training for NHC staff. TSB also assists the HSU and TAFB by performing occasional forecaster duties.

TSB is composed of a branch chief, a science and operations officer (SOO), a Techniques Development and Applications Unit (TDAU), which includes a Storm Surge Unit (section 5d), and IT specialists and programmers.

Information systems supported by TSB include a network of Linux servers and workstations, PCs, and communication hardware for the ingestion, processing, storage, and display of satellite imagery, numerical model forecasts, and observations, as well as for the generation and dissemination of NHC products. TSB programmers develop and maintain scripts to generate tropical cyclone and marine forecast and warning graphics for NHC's Web site. Two critical information systems supported and enhanced by TSB are the NCEP Advanced Weather Interactive Processing System (N-AWIPS; section 6b) and the Automated Tropical Cyclone Forecasting (ATCF) system (section 6a). The IT staff also supports the collocated FEMA and Air 


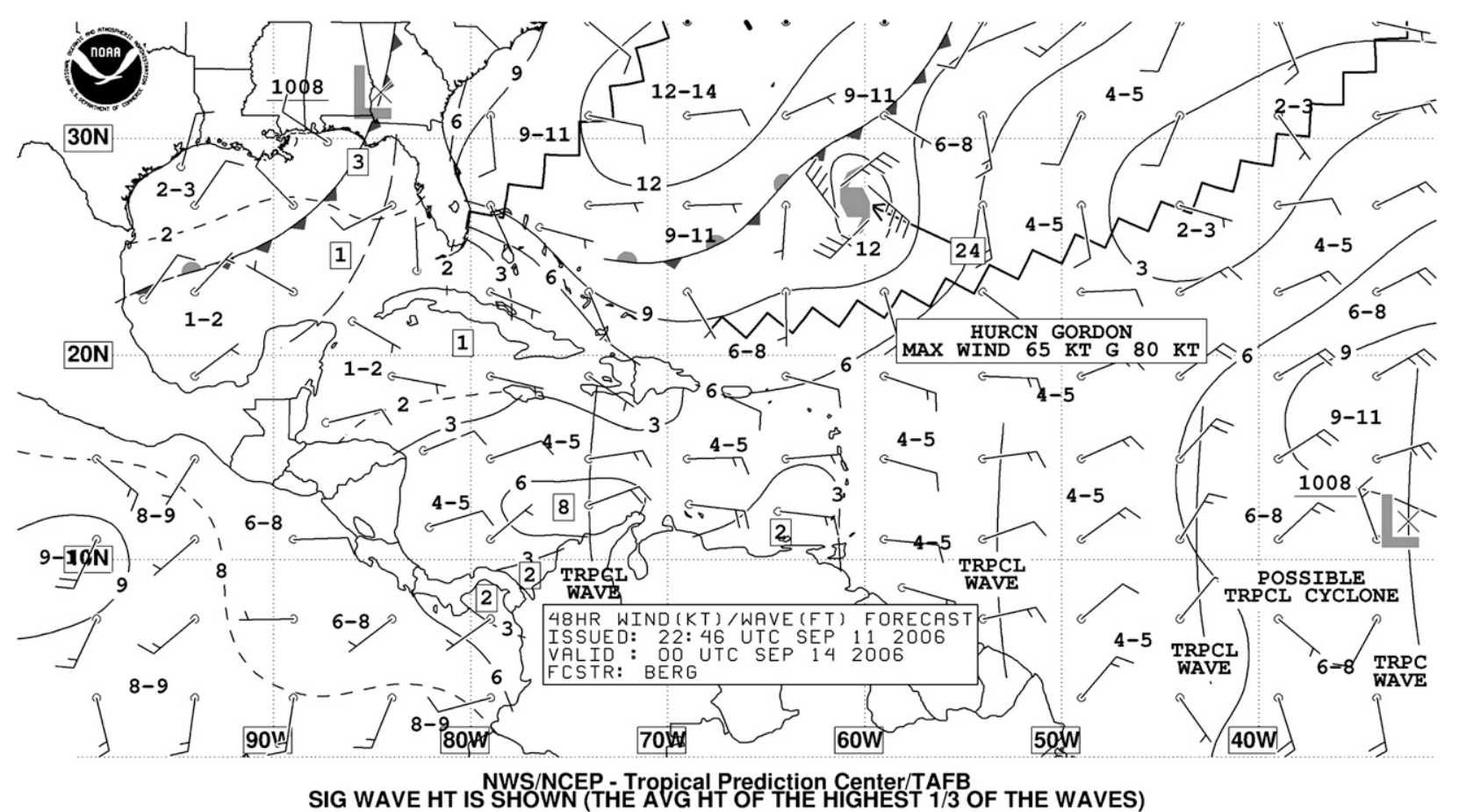

FIG. 2. Atlantic 48-h wind-wave forecast valid at 0000 UTC 14 Sep 2006.

Force Reserve units by providing them with satellite, model, and observed data, and by monitoring devices.

The SOO brings in advanced research results to the operational staff, facilitates visits by scientists, and coordinates much of the staff training.

TDAU develops and implements new techniques to improve tropical cyclone and marine analyses and forecasts. It maintains some tropical cyclone forecast models [e.g., the Climatology and Persistence (CLIPER) scheme, statistical-dynamical track schemes, and the Statistical Hurricane Intensity Prediction Scheme (SHIPS)]. TDAU governs the ATCF. It also develops techniques to facilitate the forecasters' direct use of aircraft reconnaissance flight-level and dropsonde data, and airborne and landbased radar data for tropical cyclone analysis. TDAU members participate in the evaluation of dynamical model performance.

Members of the TSB are critical to the success of the $\mathrm{JHT}$, as discussed in section 6e. TSB is responsible for bringing on line new techniques, JHT or otherwise, that NHC's director accepts for operational implementation.

\section{Tropical cyclone forecast verification}

NHC's tropical cyclone forecasts are evaluated by comparing the forecast positions and intensities to the corresponding poststorm-derived final best-track positions and intensities for each cyclone. Forecasts are in- cluded in the verification only if the system was a tropical cyclone at both the start and end times of the forecast period, known as the forecast and verifying times, respectively.

Track forecast error is defined as the great-circle distance between a cyclone's forecast center position and the best-track position at the forecast verification time. Intensity forecast error is the absolute value of the difference between the forecast and the best-track intensity at the forecast verifying time. To assess skill, the forecast error can be compared with the error from a climatology and persistence model that represents a "no skill" baseline level of accuracy. The skill baseline for track is CLIPER5, an updated version of the CLIPER model described by Neumann (1972) and Aberson (1998). The skill baseline for intensity is decay-SHIFOR, which is obtained by taking the climatology-persistence output from SHIFOR5 (Jarvinen and Neumann 1979; Knaff et al. 2003) and applying the decay algorithm of DeMaria et al. (2006) for storms whose CLIPER5 track encounters land.

Figure 3 shows average NHC official track errors for Atlantic basin tropical storms and hurricanes by decade since 1970. The 48-h forecast error is a metric tracked under the Government Performance and Results Act (GPRA) of 1993. A substantial improvement in this metric can be seen in Fig. 3; the 48-h error in the 1970s was near $250 \mathrm{n} \mathrm{mi}$, but has been near $100 \mathrm{n}$ mi in the current decade. In 2007, the verification for this GPRA 


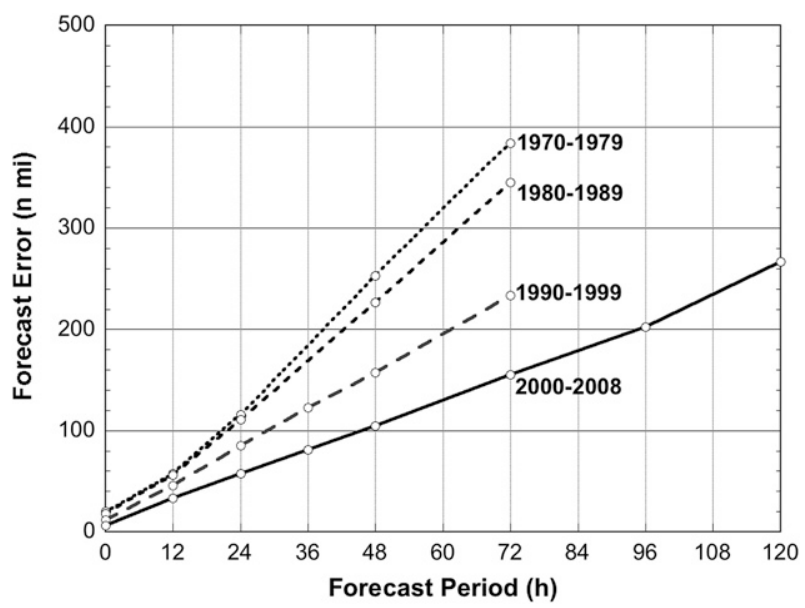

FIG. 3. Mean NHC official track forecast error for Atlantic basin tropical storms and hurricanes, by decade, for the period 1970 2008.

metric was $86 \mathrm{n}$ mi. Analysis by Franklin et al. (2003b) for the period 1970-2001 concluded that 48-h track forecasts were improving at an annual average rate of $1.9 \%$. That study also found that forecasts for storms issued while U. S. watches or warnings were in effect were improving nearly as quickly—at an annual average rate of $1.6 \%$.

Figure 4 shows the annual average Atlantic basin track forecast errors and skill for all tropical cyclones since 1990. Current errors at $24-72 \mathrm{~h}$ are seen to be roughly half of what they were in 1990, with the annual rate of improvement at $48 \mathrm{~h}$ close to $3 \%$ over this period. While the downward trend in forecast error is seen to have been relatively constant, the majority of the increased skill has occurred during the current decade.

Although the overall trend in track forecast error is downward, there is substantial year-to-year volatility, especially at the longer forecast periods. Forecast accuracy varies from one storm to the next, and even for phases of a particular storm. Figure 5 shows a 2 -week series of the 72-h track forecast verification for Hurricane Alberto (2000). The overall performance during Alberto was comparable to the 2000 season as a whole. While most of the errors were lower than the average and some were near $0 \mathrm{n} \mathrm{mi}$, two periods of very large errors occurred too. The first period corresponded to poor forecasts of "recurvature" into the westerlies while the second resulted when Alberto later unexpectedly decoupled from the midlatitude flow. This figure provides insight into the direction desired for future research. The payoff for the end user of better forecasts of the most problematic forecast situations will far exceed the gains realized by improving already "good" forecasts, for both the utility of those forecasts
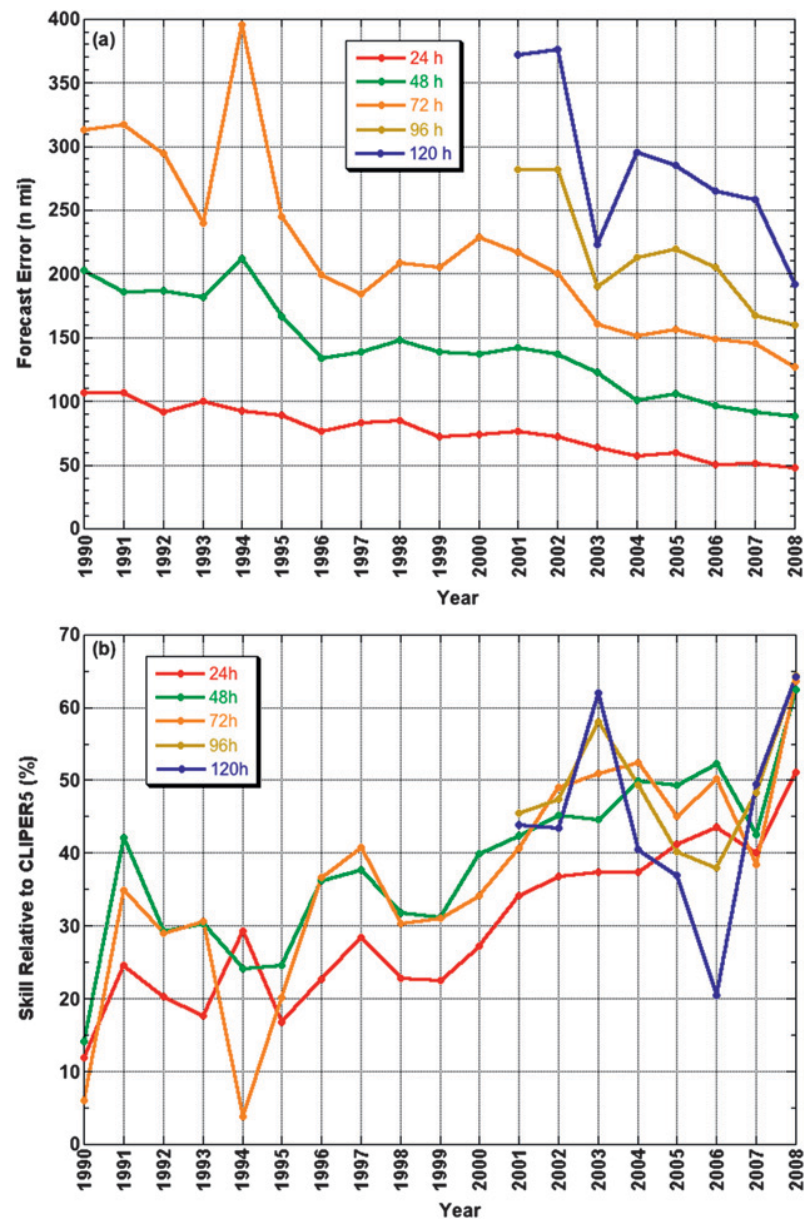

FIG. 4. Recent trends in NHC official track (a) forecast error and (b) skill for the Atlantic basin (all tropical cyclones).

as well as for the added confidence the end user would have if all forecasts were relatively good.

Less progress is seen with intensity forecasts, however, as illustrated in Fig. 6. There has been virtually no change in the accuracy of intensity forecasts since 1990 , and only a modest improvement in skill. (The anomalously low skill of the 2006 forecasts is attributed to a relatively small sample of forecasts and extremely low decay-SHIFOR errors.) The slow rate of improvement in intensity forecast accuracy and skill, and the particularly large errors that can occur in episodes of rapid intensification, have prompted NHC to elevate this deficiency to its top priority for the tropical meteorology research community.

More comprehensive verification procedures and results are given by Franklin (2008).

\section{Advances in observing systems}

Scientific, technical, and administrative advances enabled recent and ongoing changes in NHC products and 


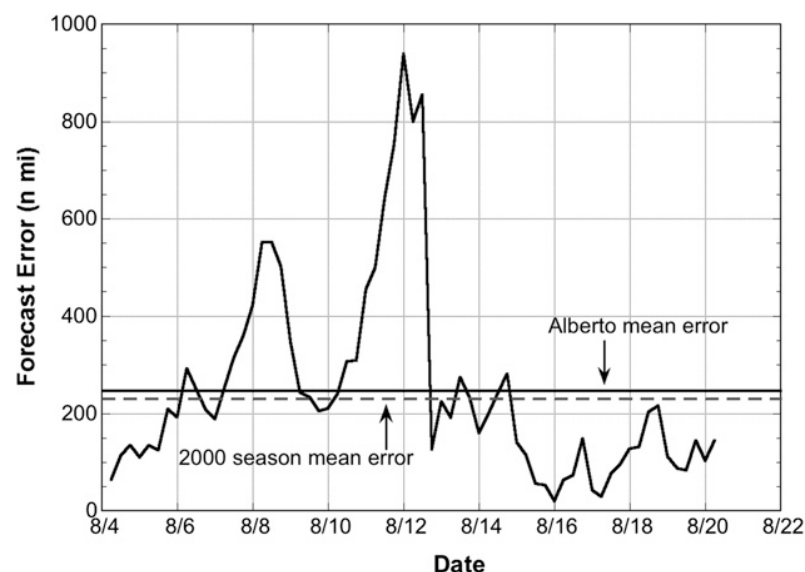

FIG. 5. Sequence of 72-h NHC track forecast errors for Hurricane Alberto (2000) made on the date shown. Horizontal solid and dashed lines show average errors for Alberto and year, respectively.

services. NWS Next-Generation Radar (NEXRAD) systems began coming into operations in the early 1990s. They have provided several capabilities anticipated by Sheets (1990), including improved center location and intensity estimates for tropical cyclones near the shore, and helpful rainfall estimates. This section describes some newer observational systems used by NHC.

\section{a. Surveillance missions with the Gulfstream-IV jet aircraft}

Efforts to improve tropical cyclone track forecasts by collecting special observations in the cyclone environment began with the NOAA Hurricane Research Division's (HRD) "synoptic flow" experiments in 1982 (Burpee et al. 1996). The success of this research program led to NOAA's procurement of a Gulfstream-IV (G-IV) jet aircraft in 1996, and the initiation of operational "synoptic surveillance" missions in 1997. The GIV is a low-wing, twin-turbofan pressurized aircraft that can fly at an altitude of $45000 \mathrm{ft}$ with a cruise speed of $440 \mathrm{kt}\left(226 \mathrm{~m} \mathrm{~s}^{-1}\right)$ and a range of 3500-4000 $\mathrm{n} \mathrm{mi}$ (White et al. 1998). During these flights, global positioning system (GPS) dropwindsondes (Hock and Franklin 1999) are released at regular intervals along the 8-9-h flight track, measuring pressure, temperature, humidity, and wind as they descend to the sea surface. During a typical mission, the G-IV releases about 25 dropwindsondes. On occasion, a NOAA P-3 or a C-130 from the 53rd Weather Reconnaissance squadron of the U.S. Air Force Reserve Command (AFRES) also releases sondes.

From 1997 through 2007, the G-IV flew 191 surveillance missions around tropical cyclones (or precyclone disturbances) posing a threat of U.S. hurricane landfall generally within 2-3 days to maximize forecast accuracy during the times when watches and warnings are
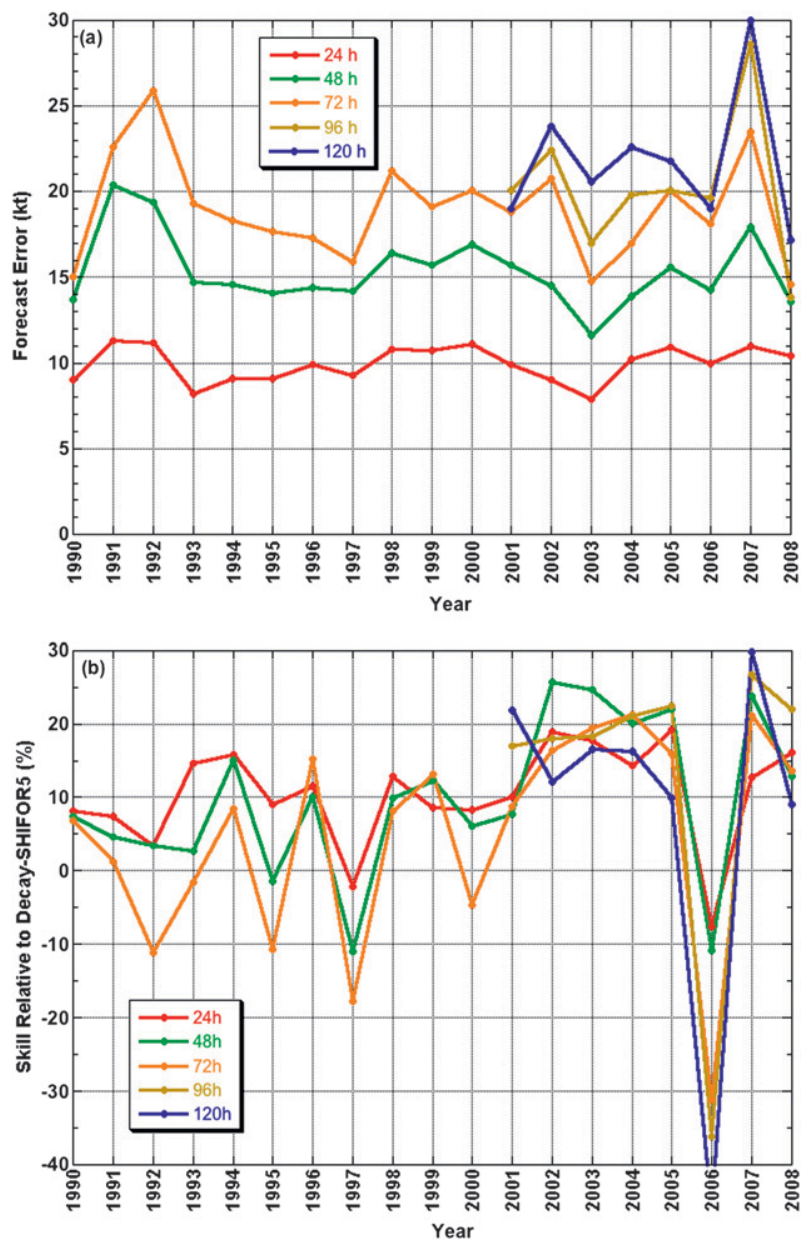

FIG. 6. Recent trends in NHC official intensity forecast (a) error and (b) skill for the Atlantic basin (all tropical cyclones).

being issued. S. Aberson (2006, personal communication) evaluated the impact of the dropwindsonde data on tropical cyclone track forecasts using the NCEP Global Forecast System (GFS) for surveillance missions occurring during 1999-2005 (Fig. 7). Consistent with the goal of improving the watch-warning process, improvements are seen to be largest through $48 \mathrm{~h}$, with the sondes having little impact on longer-range forecasts.

\section{b. GPS dropwindsondes}

Part of the G-IV jet procurement activity in the mid1990s involved a redesign of the dropwindsonde, which previously had used either Omega (Passi 1974) or loran (Passi and Morel 1987) signals for navigation. As loran signals were only available near land, and the Omega network was being phased out, a new wind-finding solution was required. In an effort partially funded by NOAA, the National Center for Atmospheric Research (NCAR) developed a modernized sonde based on GPS technology (Hock and Franklin 1999). In addition to its use during 


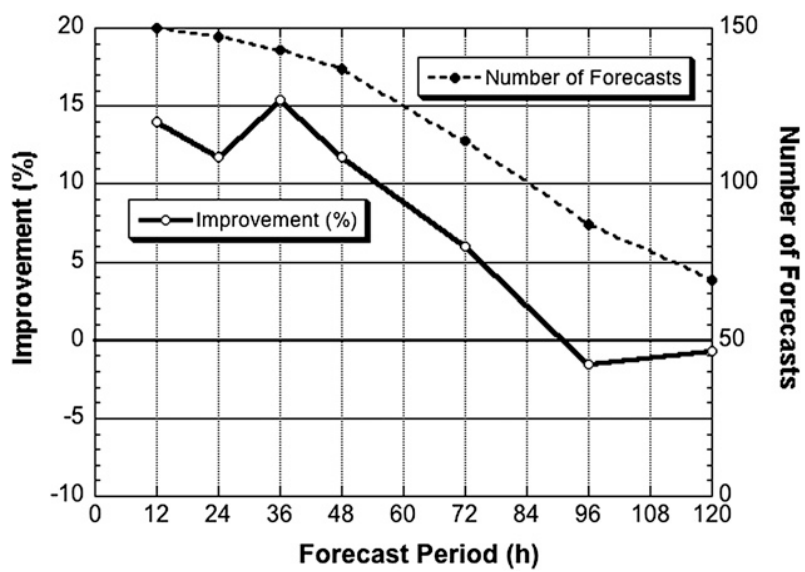

FIG. 7. Improvement in tropical cyclone track forecast accuracy from the GFS model due to dropwindsonde data from synoptic surveillance missions during the period 1999-2005. Improvement is expressed as a percentage relative to the error in a set of parallel forecasts made without the dropwindsonde data (solid line). The number of cases is shown by the dashed line.

G-IV surveillance missions in the hurricane environment, the GPS dropwindsonde quickly found an application in the hurricane core, allowing the wind and thermodynamic structure of the hurricane eyewall to be documented with unprecedented accuracy and resolution.

During 1997-99, AFRES and NOAA aircraft obtained over 400 wind profiles in Atlantic and eastern North Pacific hurricane eyewalls. These profiles allowed Franklin et al. (2003a) to determine a mean eyewall profile to relate wind speeds at flight level (typically 700 $\mathrm{mb}$ in hurricanes, $850 \mathrm{mb}$ in tropical storms) to the wind speed at the surface $(10 \mathrm{~m})$; the latter level being the one at which the intensity of a tropical cyclone is defined, but where very few eyewall observations are available. Previously, operational practice at NHC had varied over time but at that juncture was to estimate the intensity at $80 \%-90 \%$ of the flight-level value. Use of those percentages had on occasion resulted in criticism of NHC intensity estimates as being too high. The Franklin et al. study showed, for example, that the appropriate mean surface adjustment from $700 \mathrm{mb}$ was $90 \%$, and absent information to the contrary, this is the adjustment currently used by NHC to estimate hurricane intensity from that flight level.

Dropwindsonde data also provide direct measurements of surface winds. Individual dropsonde observations represent very short time scales, and they are not representative of a 1-min sustained wind in the turbulent hurricane eyewall, so these data have proven to be somewhat problematic to interpret. To obtain a more representative wind, NHC uses a vertical average computed from the lowest $150 \mathrm{~m}$ of the wind sounding that is then adjusted to the surface using the mean eyewall profile. When a sufficiently large sample of sondes is obtained in the eyewall of any particular storm, it is sometimes possible to determine that the typical $90 \%$ adjustment factor from $700 \mathrm{mb}$ does not apply.

\section{c. C-130J reconnaissance aircraft}

The 2005 season marked the full deployment of the C-130J model hurricane hunter aircraft, which replaced the aging $\mathrm{C}-130 \mathrm{H}$ fleet that had been in service since the late 1970s. The new aircraft can fly about 30-40 kt (15$21 \mathrm{~m} \mathrm{~s}^{-1}$ ) faster, $50 \mathrm{mb}$ or so higher, and with greater fuel economy than its predecessor. The C-130J also has more accurate navigation for precise positioning. Additional improvements include measured flight-level winds that are more accurate and do not degrade when the aircraft turns, improved radar displays, better displays in the cockpit for improved situational awareness, and greater comfort for the air crews. Beginning in 2008, all of the C-130Js have been equipped with SteppedFrequency Microwave Radiometer (SFMR) instruments (section $4 \mathrm{e}$ ).

\section{d. Microwave satellite sensors}

Because reconnaissance aircraft fly for only about $30 \%$ of the lifetimes of tropical cyclones in the Atlantic, and more rarely in the eastern North Pacific, visible and infrared geostationary satellite images are the primary observing tools. This imagery forms the basis of the Dvorak (1984) technique for estimating tropical cyclone positions and intensities. High cirrus clouds often obscure important lower-level convective features, however, limiting the utility of the imagery. Fortunately, passive microwave radiation can penetrate cirrus clouds and be measured by polar-orbiting satellites, revealing the convective structures below. The NOAA KLM satellite series and the Defense Meteorological Satellite Program (DMSP) employ passive microwave sensors, with data from the first of these, the Special Sensor Microwave Imager (SSM/I) coming into operational use at NHC in the late 1980s. NHC now has Advanced Microwave Sounding Unit (AMSU) sounding data to consider in its estimates of tropical cyclone intensity (Brueske and Velden, 2003; Demuth et al. 2004). The primary drawback of these observations is their intermittent availability - usually amounting to several passes over a cyclone per day at irregular intervals. Data from NASA research satellites such as the Tropical Rainfall Measuring Mission (TRMM) and the Aqua Microwave Scanning Radiometer (AMSR-E) are also used heavily by NHC forecasters. NHC accesses passive microwave imagery in near-real time primarily from a U.S. Navy Web site (Hawkins et al. 2001). The imagery is particularly 
useful for identifying the circulation centers of relatively weak tropical cyclones and for diagnosing changes in a cyclone's internal structure.

Ocean surface vector wind retrievals from the SeaWinds scatterometer, an active Ku-band $(13.4 \mathrm{GHz}) \mathrm{mi}-$ crowave instrument on board the polar-orbiting NASA QuikSCAT satellite (Hoffman and Leidner 2005), have been available in near-real time on NHC operational workstations since 2000. Although QuikSCAT was not designed for use in tropical cyclones, the data are often invaluable for identifying and locating circulation centers, estimating the intensity of tropical storms and relatively weak hurricanes, and determining the horizontal extent of winds of tropical storm force (Brennan and Knabb 2007). Improved TAFB analyses of surface features and forecasts and warnings of high-wind events outside of tropical cyclones have also resulted from QuikSCAT. TAFB began using wave height information from the Jason-1 altimeter in 2006 and data from the European Space Agency's Advanced Scatterometer (ASCAT) became available to NHC operations in late 2007.

\section{e. Stepped-Frequency Microwave Radiometer (SFMR)}

The Stepped-Frequency Microwave Radiometer is an aircraft-based instrument that measures nadir brightness temperatures at six C-band $(4-8 \mathrm{GHz})$ frequencies. Stronger winds over open waters are associated with higher amounts of foam on the sea surface, which in turn are associated with higher values of brightness temperature. The HRD with the pioneering work of Dr. Peter Black (e.g., Black and Swift 1984) has led much of the SFMR applied research. A geophysical model function (Uhlhorn and Black 2003; Uhlhorn et al. 2007) is used to relate surface emissivity detected by the SFMR instrument to estimates of wind speed below the flight track of the aircraft. Various research versions of this instrument have been installed on the NOAA P-3 aircraft since 1980. In 2005, modernized operational SFMRs were installed on the P-3s and obtained data that played a major role in the poststorm assessment of Hurricane Katrina's intensity shortly before its Gulf landfall (Beven et al. 2008). The SFMR represents a significant advancement in NHC's ability to estimate the intensity of tropical cyclones, because it lessens the need to infer surface winds from flight-level observations, or from widely spaced and relatively costly dropwindsondes.

\section{Tropical cyclone forecasting and modeling}

\section{a. Track}

The large improvements in tropical cyclone track forecasts issued by NHC over the last couple of decades
(Figs. 3 and 4) are attributed mostly to advances in numerical weather prediction guidance. Through the 1980s, statistical and/or statistical dynamical models generally provided the best guidance (DeMaria 1996). Since around 1990, however, multilevel global and regional dynamical models have become increasingly accurate and now provide superior forecasts. Better assimilation of satellite data, improved model physics, and increased resolution were keys to the advances.

The Geophysical Fluid Dynamics Laboratory (GFDL) Coupled Hurricane-Ocean Prediction System (hereafter the GFDL Hurricane Model) is based on the pioneering work of Kurihara and Tuleya (1974) and Kurihara and Bender (1980). It consists of a movable limited-area, nested-grid multilevel model with boundary conditions derived from a global prediction model. Forecast output for selected tropical cyclones was provided in near-real time to NHC in an experimental mode from 1992 to 1994, and the model immediately paid dividends with its relatively accurate track predictions for Hurricane Andrew's landfalls in southern Florida and Louisiana. The GFDL Hurricane Model became operational in 1995 (Kurihara et al. 1998). Enhancements followed, including increases in resolution, an improved treatment of moist convection, and coupling to an ocean model. The model was also upgraded to include the GFS deep convection and boundary layer schemes. These and other changes (Bender et al. 2007) have made the GFDL Hurricane Model the most accurate dynamical track forecast guidance routinely available to NHC.

While the GFDL Hurricane Model was being improved, the GFS also began to show promise as a tropical cyclone forecasting tool. Significant improvements to the GFS and its global data assimilation system occurred between 1997 and 2000 as a result of the direct assimilation of radiance measurements from polarorbiting satellites. An additional important modification to the GFS in 2000 was the replacement of the synthetic tropical cyclone vortex with a technique that removes the cyclonic vortex from the previous forecast cycle and relocates it to the observed location. A year later, additional improvements included the introduction of momentum mixing in the parameterization scheme for deep cumulus convection, prognostic cloud water, and assimilation of microwave data from polar- and nearequatorial-orbiting satellites.

The value of forecast ensembles has been long known to meteorologists. In recent years, such ensemble (or "consensus") techniques have been formally applied to tropical cyclone forecasting. One simple consensus technique (GUNA) averages the track forecasts from the GFDL Hurricane Model, the Met Office (UKMET), the Navy Operational Global Atmospheric Prediction 
System (NOGAPS), and the GFS. The power of this consensus is remarkable; for example, during the period 2004-06, the 96-h GUNA track forecast was $18 \%$ more accurate than the best performing of the four models in GUNA (GFDL). Another approach is the "superensemble" technique developed at the Florida State University (Williford et al. 2003), in which past model performance is used to determine how the component models are combined. Additional work to exploit the concept of a multimodel consensus, such as the prediction of the consensus error, and the development of corrections to the consensus track forecast to further reduce forecast errors has been done by Goerss (2007a,b). To date, ensembles based on variations of a single dynamical model (such as the GFS ensemble forecast system) have been less useful for tropical cyclone applications, although they may have utility at longer forecast periods (see section 8).

\section{b. Intensity}

Apart from the climatology and persistence model SHIFOR (e.g., Knaff et al. 2003), virtually no objective guidance for tropical cyclone intensity was available in 1990. Since that time, two other models have come into use at NHC. SHIPS was the first and became available routinely in 1993. Later combined with an overland decay model and renamed Decay-SHIPS (DeMaria et al. 2005), this statistical-dynamical model uses environmental factors (e.g., sea surface temperatures, vertical wind shear) from the GFS as predictors through a multiple-regression approach. SHIPS also includes a rapid intensification index that provides an estimate of the probability the storm will intensify by at least $30 \mathrm{kt}$ $\left(15.4 \mathrm{~m} \mathrm{~s}^{-1}\right)$ in $24 \mathrm{~h}$. Although the performance of Decay-SHIPS continues to improve slowly on a regular basis with the addition or substitution of new predictors, the model has shown limited skill over SHIFOR.

One important limitation of statistical prediction is its inherent difficulty in identifying outliers. Anticipating the rapid intensification of a tropical cyclone (e.g., Opal of 1995 in the Gulf of Mexico, or more recently 2004's Charley just prior to landfall in southwestern Florida) has long been one of NHC's greatest challenges. The global dynamical models, so successful at forecasting tropical cyclone track, lack the resolution and description of inner-core processes important to tropical cyclone intensity change. The GFDL Hurricane Model, which does have the necessary resolution to simulate some rapid changes in intensity, has lagged historically the performance of Decay-SHIPS, indicating that dynamical intensity prediction has not yet surpassed statistical techniques - a transition that for track prediction occurred 15-20 yr ago.
As noted earlier, there has been virtually no improvement in tropical cyclone intensity forecast accuracy since 1990, and only a modest improvement in skill (Fig. 6). This has occurred despite significant improvements in the quality of the intensity guidance available to forecasters over this period. In contrast to track forecasting, where improvements in NHC official forecast accuracy have been largely driven by improvements in the guidance models, the objective intensity guidance has not yet caught up with the skill of the human forecaster. Consequently, the quality of the guidance will need to improve substantially before significant improvements in NHC intensity accuracy can be expected. Section 8 below includes a discussion on how this might occur.

\section{c. Storm structure}

NHC conveys the initial and forecast size of a tropical cyclone by specifying "wind radii," the maximum radial extent of 34-, 50-, and 64-kt surface winds from the center in each of four quadrants (i.e., northeast, southeast, etc.) of a storm's circulation. During the last two decades, a number of new data sources or techniques have been applied to the analysis of storm size, including GPS dropsondes and the SFMR, as well as an improved understanding of how to adjust flight-level reconnaissance winds to the surface. These observations supplement the traditional but sparse data obtained from ships, ocean buoys, coastal platforms, and land-based stations. QuikSCAT data are often useful for determining the 34-kt radii. Low-level GOES cloud-tracked winds and wind speed retrievals from passive microwave radiometers are also utilized, but to a lesser extent. In 2003, NHC accepted for implementation a JHT project that estimates tropical cyclone wind radii from AMSU data (Demuth et al. 2004; Bessho et al. 2006).

Despite these advances, NHC has considered the observations inadequate in most cases to accurately and fully analyze the two-dimensional surface wind in a tropical cyclone. Of the instruments now available, only the QuikSCAT provides a comprehensive view of the circulation, but this instrument cannot reliably depict the distribution of hurricane-force winds, and its sensitivity to rain frequently makes determination of 34-kt wind radii difficult and the estimate less reliable. Reconnaissance aircraft, essential as they are, are available for only about $30 \%$ of Atlantic basin advisory packages (and much less in the eastern North Pacific), and even in these cases they sample a very small portion of the storm circulation. Even in the best-sampled storms, significant data gaps remain and make the operational issuance of a fully two-dimensional surface wind analysis problematic. 
At present, NHC issues 34- and 50-kt wind radii forecasts out to $72 \mathrm{~h}$, while the $64-\mathrm{kt}$ radii are forecast out to $36 \mathrm{~h}$. It also analyzes the radius of maximum wind (RMW) to help initialize atmospheric and storm surge models, but it does not forecast the RMW. Little objective guidance is available to assist the forecaster, although global models such as the GFS appear to be able to predict the gross structure of the tropical cyclone (i.e., discriminate between large and small circulations) and may have some skill in forecasting the extent of tropical storm force winds out to several days. Recently, two climatology and persistence models for the prediction of wind radii were developed by McAdie (2004) and Knaff et al. (2007). These techniques now provide some guidance for operational forecasting and eventually could serve as a baseline to measure the skill of official and model wind radii forecasts.

$\mathrm{NHC}$ began to include wind radii estimates in its poststorm best tracks in 2004. Insufficient surface observations, however, make these estimates highly uncertain and usually not possible to verify; a typical 64-kt wind radius of $30 \mathrm{n}$ mi could easily be in error by $50 \%$ or more. In contrast, tropical cyclone intensity estimates are believed to be accurate to within about $10 \%$. Any progress in forecasting storm structure will be difficult to assess with current observational systems.

\section{d. Storm surge}

Storm surge, the anomalous rise in coastal water level accompanying a cyclone, is the deadliest tropical cyclone hazard in the United States. Following frequent surgerelated disasters, the NOAA/NWS began the Storm Surge Research Project four decades ago to understand, explain, and reduce the storm surge threat. In 1980 NHC established its Storm Surge Unit to work with the NWS Meteorological Development Laboratory (MDL, formerly the Techniques Development Laboratory) to develop a numerical modeling approach known as the Sea, Lake, and Overland Surges from Hurricanes (SLOSH; Jelesnianski et al. 1992). Over the past quarter-century this work has been supported by and closely coordinated with the Federal Emergency Management Agency and the U.S. Army Corps of Engineers.

Local and state emergency managers use SLOSH model output to decide which populations to evacuate, when, and by what routes. In its primary application, several thousand runs of the model simulate the surge associated with tropical cyclones of varying intensity, size, forward speed, direction of motion, and landfall point within a model "basin." These thousands of scenarios are combined into composite maps known as maximum envelopes of water (MEOWs) and maximum of maxima (MOMs) to define the surge threat. MEOWs and MOMs are primary inputs to the hurricane evacuation studies and plans of coastal communities.

About 40 SLOSH basins span the U.S. Gulf and east coasts, and cover Puerto Rico and the U.S. Virgin Islands. The NWS revises SLOSH basins and simulations when significant changes occur to the topography and bathymetry (e.g., to levees and channels) of an area. For example, annual revisions to levees in southern Louisiana require a recalculation almost every year for that basin. Carefully prepared light distance and ranging (lidar) data should provide cost-effective updated topography and nearshore bathymetry for basin revisions. Basin revisions are time consuming; under current procedures, a revision requires the modeling of about 15000 hypothetical storms. Seventeen SLOSH basins have been restudied since 2000, but new capabilities at NHC are increasing the restudy rate.

While MEOWs are produced well in advance of a storm event, SLOSH can also be used in real time. NHC provides real-time storm surge guidance based on the single, deterministic NHC forecast for a tropical cyclone. These operational runs now begin about $24 \mathrm{~h}$ prior to the storm's forecasted landfall, and continue until the threat of rising water ceases. Given accurate meteorological forcing, SLOSH calculations are generally within about $20 \%$ of observed inundation (Jarvinen and Lawrence 1985). As an example, a poststorm SLOSH run for Hurricane Katrina using NHC best-track input is shown in Fig. 8. More than $70 \%$ of the SLOSH-calculated values are within $1.5 \mathrm{ft}(0.46 \mathrm{~m})$ of the observations; the correlation coefficient is 0.94 .

The utility of the model in real time, however, is limited by its great sensitivity to inaccuracies in NHC's forecast input of storm track, intensity, and size. For example, a $\sim 30 \mathrm{n}$ mi error in NHC forecast landfall location can make a difference of more than $20 \mathrm{ft}$ between the level of surge expected from the errant track forecast and the level of surge received. Figure 9 shows an example from Hurricane Hugo (1989) associated with such an error for a 12-h forecast. The highest surge near the onshore RMW just to the right of the hurricane's center occurred over an area that had been forecast just $12 \mathrm{~h}$ earlier to be to the left of the center and expected to experience offshore winds with little or even a negative surge. Hurricane Ivan (2004; not shown) provides a more recent example of the sensitivity of storm surge to storm track.

NHC's current mean 24-h cross-track forecast error is $39 \mathrm{n} \mathrm{mi}$. At this juncture, issuing deterministic operational surge forecasts more than about $24 \mathrm{~h}$ in advance of landfall is ill-advised because of the large and potentially life-jeopardizing errors to be expected. MEOWs indicate areas at risk that wouldn't be shown as such by a single, deterministic storm surge model run using NHC's 


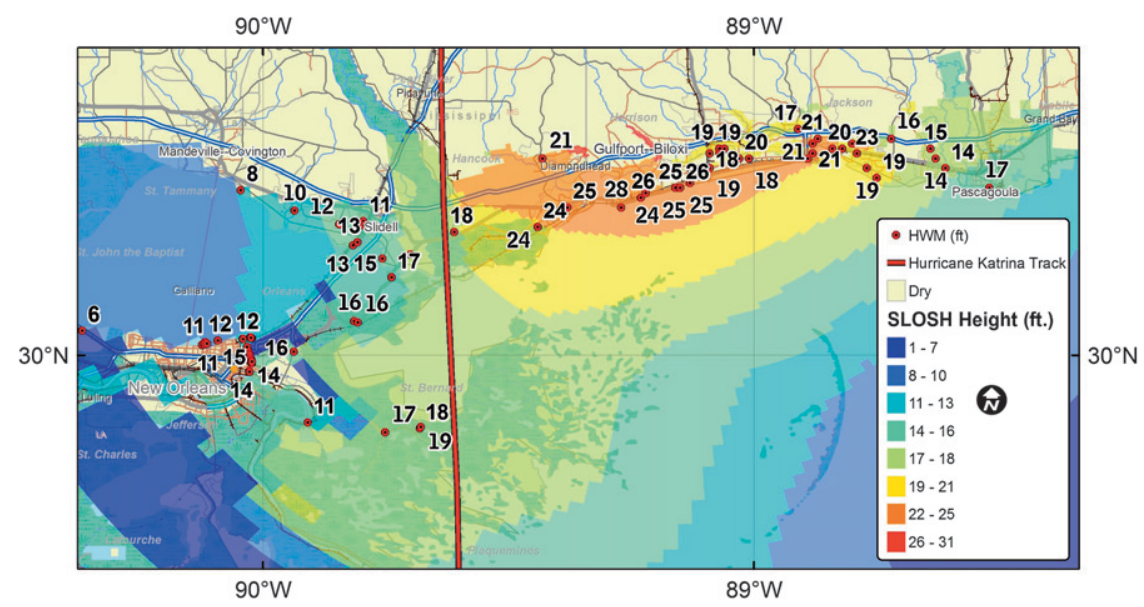

FIG. 8. Simulated vs observed storm surge along the northern coast of Gulf of Mexico for Hurricane Katrina. Shading shows surge simulated by the SLOSH model run using poststorm input including final best-track estimates of storm maximum intensity, center track (red line), and size. Plotted numbers at red dots are measured high water marks (HWMs).

forecast as input. For this reason, emergency managers use MEOWs to guide their real-time preparedness and evacuation decisions that involve lead times of $24 \mathrm{~h}$ or longer.

Poststorm SLOSH studies of such hurricanes as Charley and Isabel (2003) have added to our knowledge of the effects of storm size (parameterized in the model through RMW). Figure 10 shows the relationship between calculated storm surge and RMW; for the same track and central pressure, storms with a small RMW like Charley produce a much shallower and less widespread surge than do large RMW storms such as Isabel or Katrina. SLOSH basin updates now include an averagesized and a large RMW option.

The NWS storm surge technical work, the close relationship between the NWS and its partners, and an extensive outreach program led to the remarkable result that only about 10 people in the contiguous United States lost their lives to tropical cyclone storm surge in the 36-yr period between Hurricanes Camille and Katrina. While the large loss of life in Louisiana during Katrina was due mainly to levee failures, the many people drowned in Mississippi demonstrate that additional education and outreach about storm surge are required.

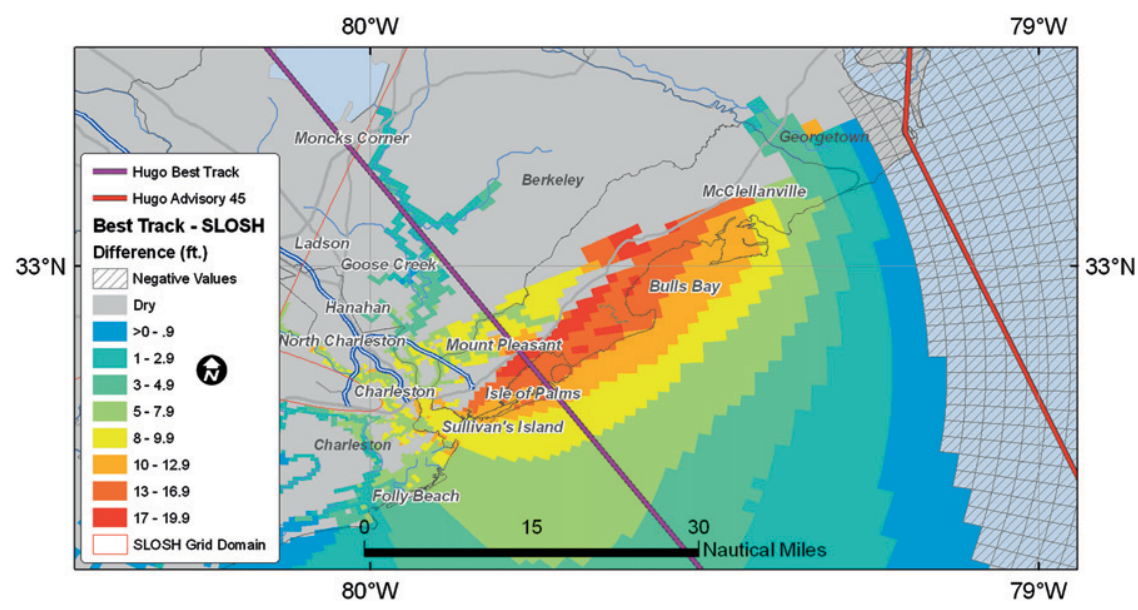

FIG. 9. Sensitivity of storm surge to hurricane track. Shading shows difference between storm surge for Hurricane Hugo (1989) simulated by SLOSH using final best-track information (e.g., purple line for center track) minus surge calculated from forecast track made $12 \mathrm{~h}$ before landfall (red line). Storm intensity and size are held constant for the calculations. 
(a)

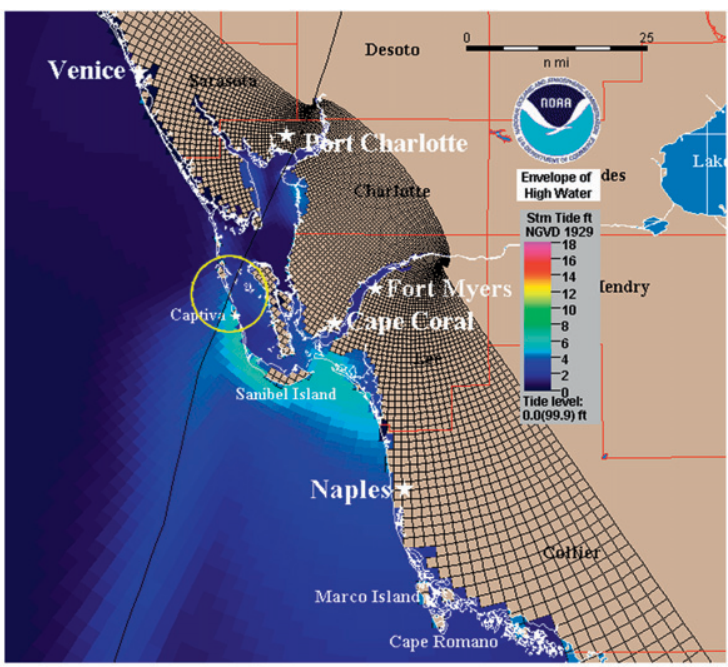

(b)

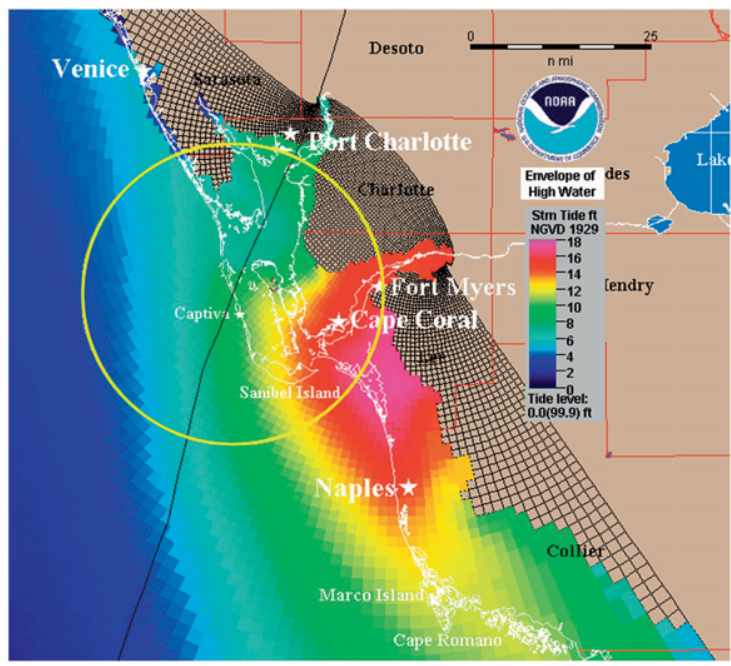

FIG. 10. Sensitivity of storm surge height and extent to storm size. SLOSH-simulated surge for Hurricane Charley run using best-track center locations (black line) but varying storm RMW (yellow circles): (a) from observed $6 \mathrm{n}$ mi RMW and (b) from larger, more typical, $23 \mathrm{n}$ mi RMW.

\section{Supporting technologies and programs}

\section{a. Automated Tropical Cyclone Forecasting (ATCF) system}

The first version of the ATCF system was developed at the Naval Research Laboratory (NRL) in Monterey, California, in the late 1980s and deployed at the Joint Typhoon Warning Center (JTWC) in Guam in 1988 (Miller et al. 1990). In 1990 the system was introduced at NHC. Before then, hurricane specialists accomplished most advisory preparation tasks manually, including the plotting of model data, or used such relatively rudimentary computer systems as the Automation of Field Operations and Services (AFOS). At that time, NHC released its Atlantic advisory packages $4 \mathrm{~h}$ after synoptic time.
The ATCF provided a multitasking software environment that improved operational efficiency, reducing the time required to prepare the advisory suite by $25 \%$. In 1992, NHC advanced the release of its products to $3 \mathrm{~h}$ after synoptic time.

Over the years, developers at NRL (e.g., Sampson and Schrader 2000) and NHC have worked together to enhance the system to meet the changing requirements of both NHC and JTWC. Today, the ATCF provides the hurricane specialists a highly specialized, end-to-end interactive interface (e.g., Fig. 11) to access and display tropical cyclone "fix" observations; update storm analyses (the "working" best track); initialize model guidance; retrieve and visualize track and intensity model output; formulate the forecast; format and generate products; and disseminate the advisory suite externally. The ATCF also contains a valuable data archive.

\section{b. NCEP-Advanced Weather Interactive Processing System (N-AWIPS)}

In the late-1990s, NHC moved much of its operational data processing and display to N-AWIPS, a software package based on the General Meteorological Package (GEMPAK) architecture. N-AWIPS provides the center with extensive processing, multisensor, and model output display (including overlay, cross section, etc.) capabilities, significantly enhancing NHC's ability to view data output over the center's area of responsibility. TAFB forecasters produce graphical products on N-AWIPS formerly drawn by hand. NHC also employs AWIPS, the version of this system used routinely by the WFOs, for radar data display and analysis during U.S. tropical cyclone landfall events.

In large part due to the capabilities of N-AWIPS, NHC now processes almost 100 times more operational data than it did $15 \mathrm{yr}$ ago and has multiple terabytes of storage capacity. The bandwidth of its local area network has increased to a GB s${ }^{-1}$ and NHC's external bandwidth has increased ten times during that period.

\section{c. Joint Hurricane Testbed (JHT)}

The National Research Council's Board of Atmospheric Sciences and Climate likened transferring some atmospheric research into forecast operations to "crossing the Valley of Death" (NAS 2000). In response to this challenge for tropical cyclones, the USWRP, with NOAA support, established the JHT in late 2000.

The JHT's mission is to transfer more rapidly and smoothly new technology, research results, and observational advances into improved tropical cyclone analysis and prediction at operational centers. This mission is accomplished by identifying promising techniques, applications, or systems being developed by external 


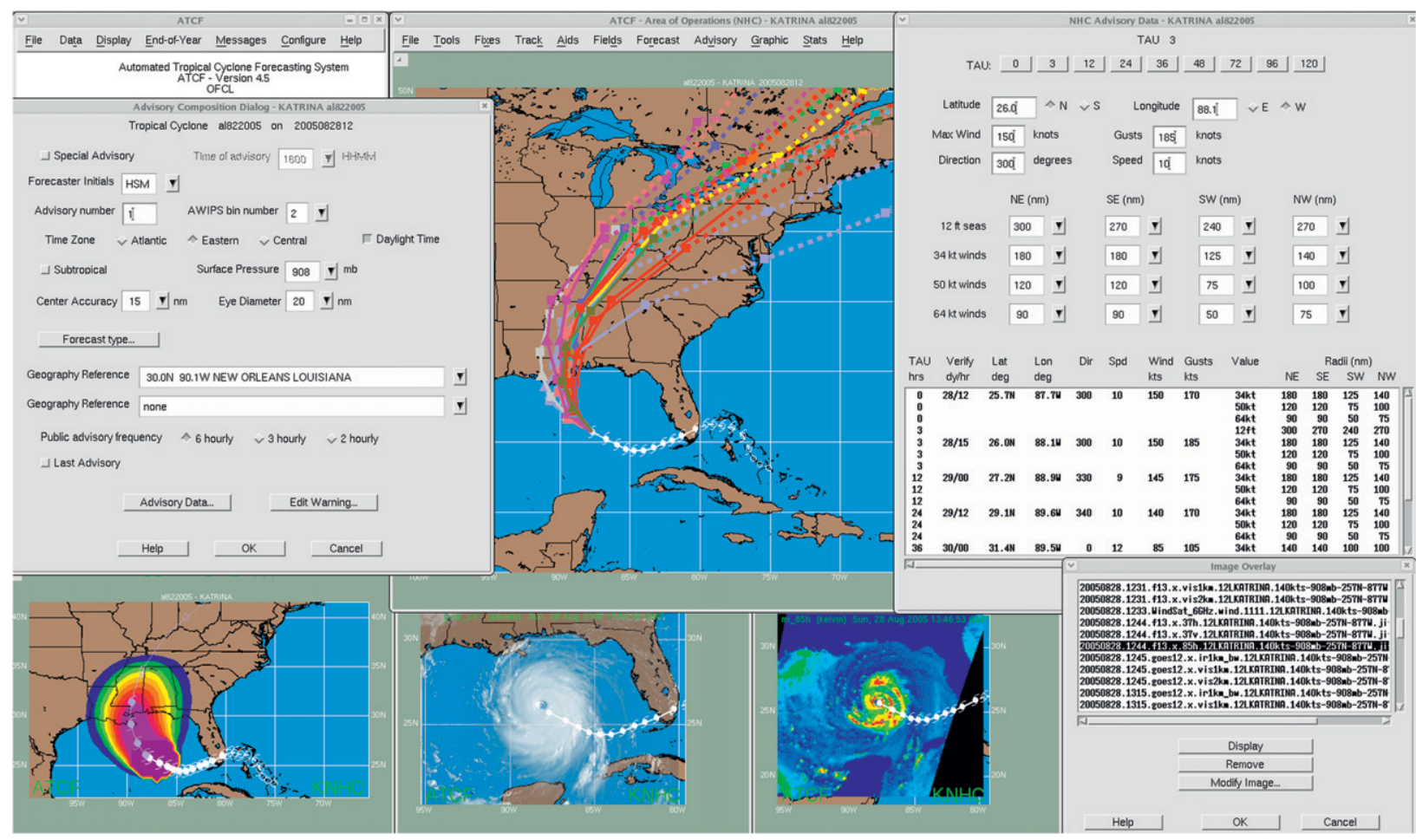

FIG. 11. ATCF display showing typical interactive graphics and dialog boxes used by hurricane specialists to analyze tropical cyclone "fix" observations and model guidance, and to construct NHC forecast products.

scientists, and by supporting their testing, evaluation, and modification in a quasi-operational environment. The JHT is governed by a terms of reference document, summarizing its organization and operation. The JHT has been centered initially at NHC.

Federal assistance through NOAA has been provided to scientists to allow them to tailor their techniques for the operational environment. The total annual JHT budget has varied between about $\$ 1$ and 1.5 million, most of which has been made available to fund proposals submitted by the research community. Although the JHT provides funding for its infrastructure, it relies on NHC for critical forecaster, administrative, technical, and logistical support. NHC contributes, cumulatively, approximately 1.5 staff members as technicalscientific "points of contact," as well as administrative and IT programming support. The TSB maintains JHT computer equipment, provides real-time data, and collaborates with project investigators to facilitate testing and evaluation. Researchers also work with other national centers [e.g., the Environmental Modeling Center (EMC) and the HPC] with facilitation provided by the JHT.

Administration of the JHT is provided by a quartertime director (the TSB chief), two quarter-time administrative assistants (one is the TSB SOO), and one full-time IT facilitator. The JHT Steering Committee advises the JHT director on all JHT activities, and its primary responsibility is to review proposals submitted to the JHT by the research community. The steering committee comprises seven members, including representatives from NOAA and DOD tropical cyclone operations and research, as well as academia. A JHT IT infrastructure, separate from but similar to an operational center's IT environment, is required for robust testing and evaluation without imposing unnecessary distractions, risk, and expense upon the operational center.

Availability of JHT funds for the research community is advertised via the periodic publication of a JHT Announcement of Federal Funding Opportunity (AFFO). The AFFO has thus far been published approximately every other year in step with a nominal 2-yr project cycle. It includes the program objectives and priorities and proposal submission requirements. For example, the AFFO contains a list of NHC and EMC analysis and forecast improvement needs that have been identified and prioritized by these centers. Most researchers worldwide are eligible to submit proposals as part of a competitive process. Proposal evaluation criteria are the scientific merit of the technique, readiness for real-time testing based on factors like research maturity, analysisforecast issue priority, technical compatibility with operational systems, and costs. 
After one or two years of testing, the conclusion of a JHT project is followed by the submission of a final JHT report to NHC's director [and/or other operational center(s) if applicable]. This report comes from the JHT staff and is based on its evaluation and input from the project scientist(s) and NHC's points of contact. NHC's director makes the decision on whether or not to begin the process of operational implementation of the techniques resulting from the project. (Decisions on model changes are made at NCEP, with NHC input.) The NHC director's decisions are based on an analysis of (a) forecast or analysis benefit, (b) efficiency, (c) IT compatibility, and (d) sustainability.

Since the JHT's inception, NHC and other operational centers (e.g., EMC, HPC, and JTWC) have interacted with scientists on 40 projects in three 2 -yr rounds and, of these, 31 have been implemented into operations, 4 were not accepted, and 5 are undergoing additional testing. Ten fourth-round projects are under way.

Some improvements in tropical cyclone monitoring and prediction in recent years can be credited to the successful implementation of JHT projects. For example, Elsberry (2005) reported that the USWRP goal for reducing tropical cyclone track forecast error by $20 \%$ over a 5-yr period was in large part accomplished through model advances sponsored by JHT funding. M. DeMaria (2006, personal communication) attributes about a 5\%$7 \%$ improvement in the SHIPS intensity forecast technique to JHT work. Other contributions include accelerating development of the Hurricane Weather Research and Forecast (HWRF) model (section 8), NHC's new wind speed probability products (section $7 \mathrm{~b}$ ), and extension of the coupling of the GFDL model to the eastern and central North Pacific through development of a one-dimensional version of the Princeton Ocean Model.

Additional JHT information is available online (www.nhc.noaa.gov/jht).

\section{New products and services}

In addition to expanding its area of responsibility, extending its temporal forecast horizon, and providing information in new ways, NHC has introduced many new operational products since 1990. Most of these are graphical, while some are gridded, some are textual, and some are in new formats including Geographic Information Systems (GIS) compatible. Among the newest operational products is an experimental graphical tropical weather outlook that serves as a companion to the text outlook, and experimental probabilistic storm surge forecasts developed by the NWS MDL, available graphically on NWS Web pages. The latter product uses SLOSH to compute the surge from the official forecast track and reasonable alternate possibilities. New TAFB products include textual offshore waters forecasts and marine weather discussions. TAFB has also added wind-wave charts, wave period-swell direction charts, sea-state analysis maps, surface forecast charts, high wind and associated seas charts, and marine "danger area" graphics. In 2006, TAFB began generating experimental grids of significant wave height out to $48 \mathrm{~h}$.

Details on a few of the key new activities at NHC are presented below.

\section{a. Internet}

With the capability of creating graphics in a more timely and effective manner, NHC designed and launched a Web site in the early 1990s as a way to quickly reach more users. NHC's Web content and prominence on the Internet have grown enormously since the Web site (http:// www.nhc.noaa.gov, and now also http://www.hurricanes. gov) was launched as a limited collection of pages created and maintained by the TSB. In 1995, NHC enhanced the Web site and hosted the service on a developmental computer system sharing communications lines with NHC operations. Hurricane Felix (8-25 August 1995) produced 250000 hits per day and resulted in occasional Web site crashes.

Since then, the Web site has steadily gained in popularity. A peak traffic count of 1.1 billion hits per day occurred during Hurricane Wilma in October 2005, and the Web site served 7.4 billion hits that year. The NWS has upgraded the NHC Web site processing, capacity, and redundancy to help meet the demand. Since 2004, an outside vendor has hosted NHC's Web site during high-traffic periods. Enhancements include an NHC backup Web server located at HPC.

NHC's Web site has a history of integrating new technologies. Web graphics were introduced in the middle 1990s to show basic tropical cyclone characteristics, strike probabilities, and tropical cyclone watches and warnings. Additional graphics followed and now account for about $80 \%$ of the traffic on the site. A tropical cyclone advisory mailing list, introduced in 2001, sends NHC advisories to over 60000 subscribers, and upward of 1 million messages are sent daily during multiple tropical cyclone events. In 2002 the Web site introduced the use of Really Simple Syndication (RSS) feeds for newsreaders and mobile products for use on handheld personal digital assistants (PDAs) and the system was expanded in 2004 to include graphics.

Today, the Web site provides most of NHC's operational text and graphical products from the HSU and TAFB, product tutorials, an extensive historical archive, climatology information, hurricane preparedness guides, and links to federal and state emergency management 
agencies. It also has pages describing NHC's forecast process and forecast verification, and other frequently requested hurricane information.

\section{b. Tropical cyclone wind speed probabilities}

NHC has long issued products intended to convey uncertainties in the official forecast. A "strike" probability product for Atlantic basin cyclones was introduced in 1983 (Sheets 1985). NHC also provides a graphic showing watches and warnings, the track forecast, and an associated "cone of uncertainty" based on recent error statistics. Another product gives probabilities for the cyclone's future maximum wind speed. In addition, the tropical cyclone discussion text product describes the reasoning and uncertainties associated with each forecast.

Recognizing the need to more clearly convey uncertainties in its forecasts, NHC in 2006 began issuing tropical cyclone surface wind speed probability products. Figure 12 shows an example of one of these new products. The wind speed probabilities represent a major advance over previous efforts, for the first time explicitly and objectively considering the combined uncertainties in the forecasts of storm track, intensity, and size. They indicate in text and graphical form sitespecific chances of experiencing sustained wind speeds equal to or exceeding familiar thresholds (e.g., tropical storm force and hurricane force), as well as guidance on when those wind conditions are most likely to start. The wind speed probabilities are intended to provide users with information that enhances their ability to make preparedness decisions specific to their own situations. Positive feedback from the media and the emergency management community indicates these products are used along with other NHC products for decision making and risk communication. The probabilities are also available to users via the NWS National Digital Forecast Database (NDFD), and WFOs use a form of the probabilities in some of their products.

\section{c. Best-track database}

After the conclusion of each Atlantic and eastern North Pacific tropical cyclone, the HSU prepares a final best track, a subjectively smoothed representation of the tropical cyclone's location, intensity (as maximum sustained surface wind speed), minimum sea level pressure, and size over its lifetime at 6-hourly intervals. These estimates are based on a comprehensive analysis of all available observational data, generally gathered within several weeks after the system's conclusion, and they differ frequently from operational estimates. Once completed, the best tracks are added to HURDAT, the historical tropical cyclone database. The data are also archived in the ATCF. Currently, the HURDAT con- tains best tracks from 1851 to the present for the Atlantic basin (Jarvinen et al. 1984; Landsea et al. 2004a) and from 1949 to the present for the eastern North Pacific basin (Davis et al. 1984). The best-track data are used at NHC for verification of forecasts and other internal applications. They are also used extensively by the research, academic, and insurance communities, as well as by the media and the public.

Best-track files are not static, but are subject to revision as new data or understanding comes to light. Landsea (1993) and Neumann (1994), for example, documented many systematic and random errors in HURDAT. In addition, through inspection of historical meteorological records and accounts, previously unknown tropical cyclones can be identified as potential additions to the database (Fernández-Partagás and Diaz 1996). Landsea et al. (2008) describe an ongoing HURDAT reanalysis project dealing with these issues.

NHC's Best Track Change Committee receives proposed amendments to HURDAT and evaluates them based on observational data and sound, contemporary science. The committee has the authority to make official changes to the best-track files. After approval by the committee, the revised tropical cyclone database, a metadata file detailing individual changes for each tropical cyclone, a "center fix" file of raw tropical cyclone observations, a detailed listing of U.S. landfalling tropical storms and hurricanes, and comments of NHC's Best Track Change Committee are prepared. They are available online (http://www.aoml.noaa.gov/hrd/data_sub/re_ anal.html).

Recently, an extension of the Atlantic HURDAT from 1885 back through 1851 was completed, and a reassessment was conducted for tropical cyclones already in HURDAT for the period of 1886-1920 (Fernández-Partagás and Diaz 1996; Landsea et al. 2008). These alterations added 274 new tropical cyclones and modified another 231 of the 517 total storms identified between 1851 and 1920 .

Also of interest is a reanalysis of a more recent storm, Hurricane Andrew (1992), based in part on new understanding of the wind structure in the hurricane eyewall (Franklin et al. 2003a). The reanalysis indicated that Andrew's maximum 1-min surface winds for much of its lifetime were stronger than analyzed originally by NHC. The HURDAT database was revised to show Andrew at Saffir-Simpson hurricane scale category 5 status at its landfall in both the northern Bahamas and in southeastern Florida (Landsea et al. 2004b).

\section{d. Partnerships, outreach, and education}

Former NHC Director Max Mayfield stated "the battle against the hurricane is won outside the hurricane season," and the tragic loss of life from Katrina reminds 


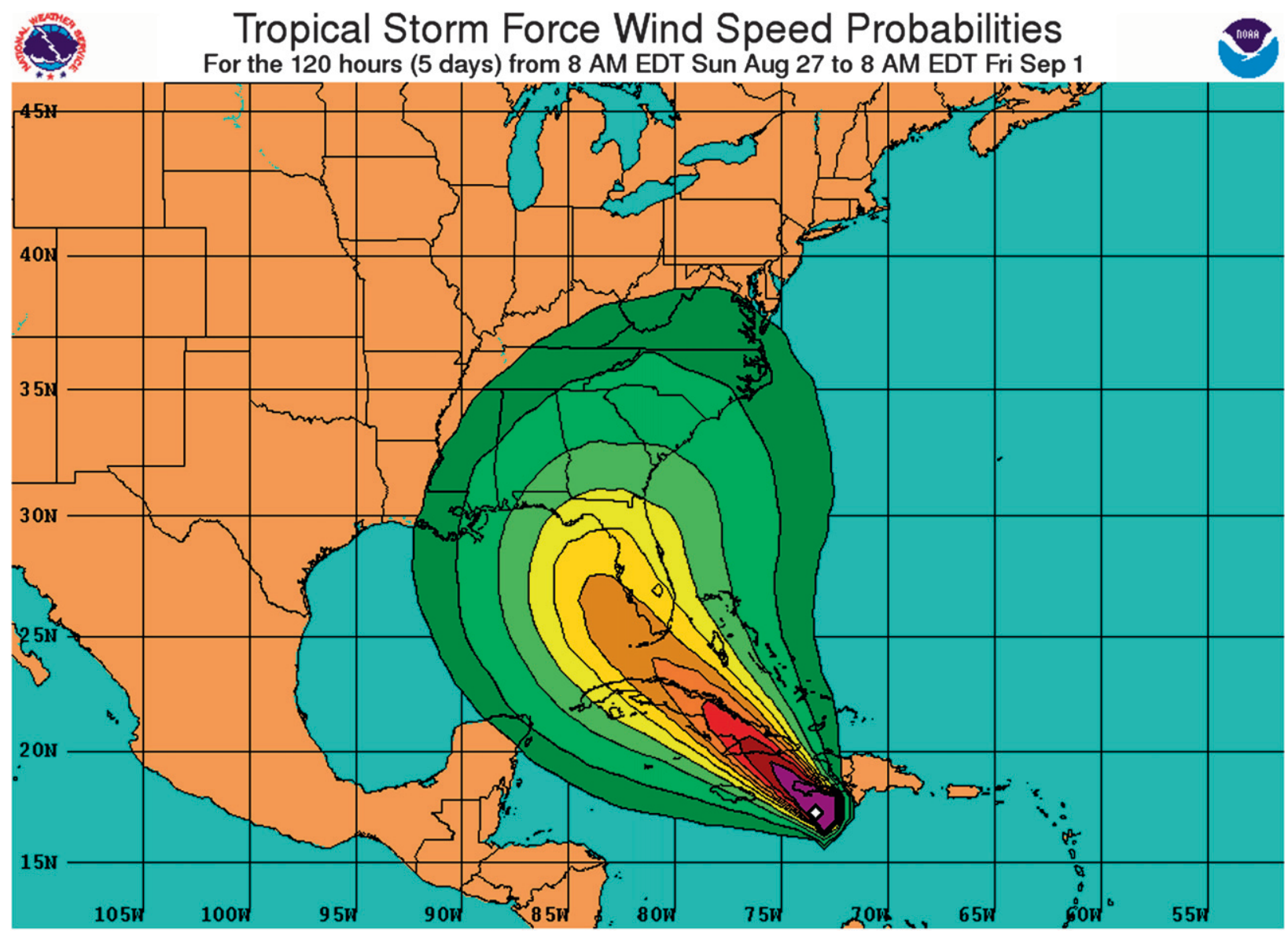

Probabilities of sustained tropical storm force surface winds (1-minute average of $39 \mathrm{mph}$ or greater) from all active tropical cyclones $\diamond$ indicates HURRICANE ERNESTO center location at 8 AM EDT Sun Aug 272006 (Forecast/Advisory \#12)

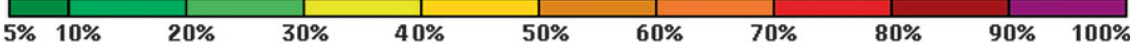

FIG. 12. Wind speed probabilities graphic for Hurricane Ernesto (2006), NHC Advisory 12, showing cumulative probabilities of sustained wind speeds of at least $34 \mathrm{kt}$ (tropical storm force) occurring at any point on the map during the 5-day period beginning 0800 EDT 27 Aug 2006.

us that an accurate forecast of a hurricane does not by itself ensure a successful result. It is worth noting, however, that an even greater loss of life would have occurred had it not been for the high evacuation rates, estimated to have been near $80 \%$ for New Orleans. This was an unusually high rate for such a large community (e.g., Cooper and Block 2006) and was likely due, in part, to the effectiveness of offseason outreach and education efforts. Such efforts include annual hurricane conferences, workshops, training sessions, week-long hurricane awareness tours in this country and abroad, as well as the partnerships between the NWS, emergency managers, and the media. NHC's director dedicates about two-thirds of his time during the off-season to outreach efforts, and many other NHC staff members participate in these kinds of activities as well. One such activity is the National Hurricane Survival Initiative, a public-private partner- ship promoting preparedness, which has found that around half of the families living in hurricane-vulnerable areas have yet to prepare a hurricane plan. This shows clearly the need for additional outreach efforts.

The NWS maintains a strong partnership with the emergency management community. Each year, FEMA supports three 1-week-long workshops at NHC attended by local and state emergency managers. The goal is to educate emergency managers on hurricane basics, forecast uncertainty, and storm surge. Since the first course in the early 1990s, about 1000 state and (mainly) local officials from U.S. Gulf and east coast communities have been trained at these workshops. Similarly, NHC conducts an annual 2-week WMO-sponsored workshop for international meteorologists.

Several critical collaborations enhance NHC operations. NHC initiates a "hurricane hotline" call approximately $1 \mathrm{~h}$ 
prior to the advisory release deadline or whenever a special advisory has been prepared to discuss preliminary forecast information with its government partners. Participants include WFOs and NWS River Forecast Centers; rainfall and tornado experts from the HPC and Storm Prediction Center, respectively; OPC; NWS national and regional headquarters; and meteorologists at some U.S. Naval sites [e.g., at the navy's Norfolk facility (Naval Maritime Forecast Activity, formerly Atlantic Meteorology and Oceanography Command)] and at NASA. It is important to note that WFO meteorologists contribute their local expertise when they pass the information on to emergency managers and other local officials in their areas of responsibility.

The NWS and FEMA together created the Hurricane Liaison Team (HLT) in 1995. The HLT partnership ensures access by emergency managers to forecast information they need to make decisions. Once activated, one or more emergency managers are sent to NHC to support hurricane response operations through the rapid exchange of critical information between NHC and emergency managers at all levels of government. The HLT establishes and facilitates daily video teleconferences and more frequent audio teleconferences during landfall threats; responds to emergency management questions and concerns; directs weather-related questions to NHC, HLT NWS meteorologists and hydrologists, or WFOs; and relays emergency management issues to the NWS. The NWS provides meteorological briefings for FEMA and other federal agencies, and state emergency operation centers. Department of Homeland Security staff and the White House sometimes participate in these briefings.

During a U.S. hurricane landfall threat, NHC can activate a media pool, providing access to television stations and networks across the nation. Briefings seek to highlight storm information, indicate potential impacts, and provide perspective. NHC's Web graphics are also an important part of this communications process.

In 2004-05, NHC's director and deputy director each gave more than 1000 live television briefings (mostly in the form of 4-min time slots) during landfall threats. On occasion, some NHC senior hurricane specialists give these briefings. NHC staff also provides many thousands more briefings via telephone. These briefings help NHC and its media partners deliver a consistent message, which behavioral scientists say is key to ensuring that people respond quickly and appropriately to approaching threats (Mileti 1999). Sheets (1990) discussed two cases where information conflicting with NHC's official forecast led to problems with community preparations.

Freshwater floods from rainfall present the primary tropical cyclone threat to life in inland areas (Rappaport
2000). The NCEP director in 2005 assigned lead responsibility for U.S. tropical cyclone precipitation forecasts appearing in NHC public advisories to the HPC. With a few special exceptions, NHC transfers responsibility to HPC for the entire public advisory when a cyclone weakens to a tropical depression over the mainland United States or Mexico and still poses a threat for heavy rain and flash floods affecting the United States. The HPC also serves as the backup office for the HSU. OPC backs up TAFB. NHC has backup responsibilities for the Central Pacific Hurricane Center, OPC, WFO Honolulu, and the Aviation Weather Center over the areas indicated in Fig. 1.

All of these collaborations help ensure the best possible outcome during hurricanes and other weather events.

\section{Forecast for the forecast}

Atlantic tropical cyclones have killed an estimated one-third to one-half million people since the discovery of the New World, including more than 25000 in the United States (cf. Rappaport and Fernandez-Partagas 1995; Blake et al. 2007). Today, more than $50 \%$ of the U.S. population lives along the coast (Crossett et al. 2004), and annual average U.S. property losses incurred from hurricanes have jumped to more than $\$ 20$ billion [see data since 2000 in Table 3a of Blake et al. (2007)]. By 2010, the population density near the U.S. shore is projected to rise to around 400 people per square mile (NAS 2004), putting increasing numbers of people and their property at risk from tropical cyclones. It is clear that our nation's increasing vulnerability to tropical cyclone hazards must be met with significant further advances in the nation's hurricane program.

The roughly $80 \%$ evacuation rate estimated for Hurricane Katrina provides a measure of the progress of the nation's hurricane program enterprise. The $20 \%$ who stayed behind, on the other hand, can give us insight into the challenges faced by NHC and its partners, especially to the extent that their decisions to stay reflect that they 1) did not receive the forecast information, 2) received forecast products of inadequate accuracy or breadth, 3) did not understand the forecast information or its implications, and/or 4) did not believe the information.

Addressing these issues requires improvements in all areas of the hurricane program. For forecasting, better tropical cyclone genesis, track, wind intensity, storm surge, and rainfall predictions are necessary, along with better ways to depict the threats. Some of NHC's highest priority specific near-term needs include the following:

guidance for tropical cyclone intensity change, with the highest priority for the onset, duration, and magnitude of rapid intensification and weakening events; 
improved observational systems in the storm and its environment that provide data for forecaster analysis and model initialization;

statistically based real-time "guidance on guidance" (e.g., multimodel consensus approaches), provided to forecasters in probabilistic and other formats;

improved model forecasts of track, especially to reduce large speed errors (e.g., on recurving or stalling storms) and large direction errors (e.g., on loops), and on specific forecast problems (e.g., interaction with terrain);

operational analysis and forecast of the surface wind field;

guidance for tropical cyclone genesis;

guidance on the operational utility and relative merits of high-resolution model output compared to lower-resolution ensemble model output;

guidance for tropical cyclone precipitation amount and distribution; and

improved utility of microwave satellite and radar data in tropical cyclone analysis.

NHC expects operational numerical weather prediction model advances will continue to drive forecast improvements. Global models like the GFS, NOGAPS, UKMET, and that of the European Centre for MediumRange Weather Forecasts (ECMWF) are among the frontrunners in tropical cyclone track forecast accuracy, and are also important components of intra- and intermodel ensembles. The performance of global models at longer time periods will be a factor in deciding when the forecast period for NHC can again be extended for tropical cyclones. When NHC introduced 3-day predictions in 1964, the average Atlantic track forecast error for 3 days was near $400 \mathrm{n}$ mi. The 5-day forecast errors averaged near $375 \mathrm{n}$ mi when they were first issued in 2003. An initial verification of longer-range GFS track forecasts is shown in Fig. 13. This verification covers the latter portion of 2005 and 2006-07. The average error for 7 days for the sample is near $525 \mathrm{n} \mathrm{mi}$ for the GFS. The 7-day errors for the GFS ensemble mean are much lower, near $375 \mathrm{n} \mathrm{mi}$, and could indicate a particular value of intramodel ensembles for extended-range forecasts. Because the GFS ensemble mean errors increase at a nearly linear rate, it is likely that if the shortperiod errors continue to decrease, so might the longerperiod errors in a commensurate fashion.

The GFS is also important for the boundary conditions it provides to regional hurricane models. It is the background for a highly sophisticated, new regional numerical model for the prediction of tropical cyclones, known as the Hurricane Weather Research and Forecast (HWRF) model, which became operational at NCEP in time for the

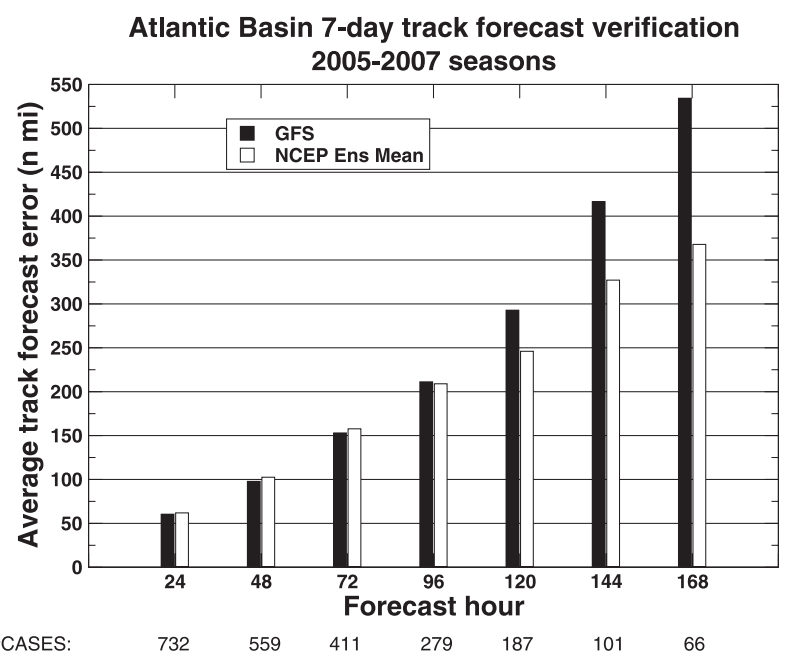

FIG. 13. Average Atlantic track forecast errors for GFS and GFS ensemble means for latter part of 2005, and for 2006-07.

2007 hurricane season. HWRF makes use of the WRF community-based infrastructure. It is a coupled air-sealand prediction model with a movable nested grid and advanced physics for high resolution. HWRF uses nonhydrostatic mesoscale model dynamics, for example, the Nonhydrostatic Mesoscale Model (NMM) core (Janjić et al. 2001). Its initial operational configuration consists of $9-\mathrm{km}$ horizontal resolution with 42 vertical levels. This initial capability, along with plans for further improvements in physics, data assimilation, horizontal and vertical resolution, and coupling over the next several years, provide a framework for improving tropical cyclone forecast track, wind intensity and distribution, and rainfall forecasts.

HWRF initialization and the associated advanced data assimilation techniques for the hurricane core are being developed to make use of real-time airborne Doppler radar data from NOAA's aircraft to initialize the three-dimensional storm-scale structure. This work is expected to prove beneficial in improving hurricane intensity and structure forecasts. To address the totality of the hurricane forecast problem, including improved prediction of coastal and inland inundation, future versions of the HWRF will be coupled to an advanced version of NCEP's wave model, for example, WAVEWATCH, and to a dynamic storm surge model. Shallow water physics are being introduced into WAVEWATCH for forecasting waves at the immediate coastline. In addition, the land surface component will serve as input to hydrology and inundation models to address the hurricane-related inland-flooding problem (Surgi 2007).

New observing capabilities will benefit NHC, both indirectly through their impact on operational forecast 
models, and directly as applied by the forecasters. With the increasing emphasis on oceanic contributions to tropical cyclone forecasting, it should be expected that additional sensors measuring routinely, for example, oceanic heat content and other surface and subsurface conditions will also likely provide important information (e.g., Mainelli et al. 2008). So might other sensors and platforms currently under consideration (e.g., unmanned aerial systems) or not yet envisioned.

NOAA plans to implement a new generation of operational polar and geostationary satellites early in the next decade. The new polar system (the National PolarOrbiting Operational Environmental Satellite System; NPOESS) is a joint venture with the Department of Defense. It will include a number of advanced instruments with tropical cyclone applications. For example, NPOESS will include microwave and infrared sensors with vastly improved vertical and horizontal resolutions to provide much more accurate temperature and moisture profiles than are now possible. The next-generation GOES satellites, beginning with GOES-R, will include an advanced imager with more than three times the number of channels, higher horizontal resolution, and much faster scanning rates than current GOES satellites. GOES-R will also include a lightning mapper, which has potential application to intensity analysis and prediction. The Joint Center for Satellite Data Assimilation (LeMarshall et al. 2007) is a collaborative effort between NOAA and NASA that will help to develop the assimilation techniques needed to extract the information content for model initialization from these and other new satellite systems.

NHC looks forward to the eventual deployment of sensors to measure accurately and at high-resolution the surface wind circulation (e.g., an operational nextgeneration version of the QuikSCAT satellite), and eventually the entire three-dimensional wind field in the storm and its environment. Such a capability, along with improved analysis and display tools, for example, in storm-relative coordinates, and on AWIPS II, the planned successor to AWIPS and N-AWIPS), would improve tropical storm and hurricane watch-warning issuances by enabling NHC to better analyze, forecast, and verify the maximum intensity and specific wind radii now contained in its advisories, and to extend the forecast period of those radii to match the longer period of NHC's track forecasts. These data and improved numerical models could also make it possible for NHC to meet its long-desired objective of issuing operational surface wind forecasts.

Storm surge remains a tremendous threat to life. New ways of depicting the threat, like the probabilistic products mentioned in section 7 , along with expected ad- vances in atmospheric and associated surge models, should some day make it possible to issue explicit storm surge warnings for the U.S. coasts. Such warnings would not necessarily be the same as current NWS warnings based primarily on wind speed criteria. This may be particularly effective in helping to better distinguish between impact-specific threats and their associated preparedness options in hurricanes (e.g., to promote "fleeing from the water but hiding from the wind").

The improvements in numerical model track forecasts have enabled NHC in recent years to trim the average length of its U.S. coastal hurricane warnings (Fig. 14), while increasing lead time (M. DeMaria 2007, personal communication). Further reductions in warning lengths are desirable if they decrease "overwarning," but should not be made if they expose unwarned areas to hurricane conditions. A review of recent U.S. hurricane warnings indicates that a $25 \%$ decrease in warning length would have resulted in hurricane conditions occurring outside of hurricane-warned areas in several systems, including Hurricane Ivan (2004). Consequently, additional major reductions in warning size likely await significant further improvements in model guidance. In the meantime, NHC is working with JHT-funded scientists to look at whether the placement and timing of these warnings can be improved and made more objective by considering output from NHC's new wind speed probability programs.

NHC has pioneered within the NWS some new ways for communicating information. When NHC introduced its computer-generated tropical cyclone graphics during a national television briefing announcing a hurricane watch for the U.S. southeast coast for Hurricane Hugo (1989), it marked a first for the NWS. That effort led to NHC's Web site graphics discussed in section 7a. Among its current new activities, NHC has begun making experimental in-house probabilistic forecasts of tropical cyclone genesis and probabilistic forecasts of rapid intensification. It is also working toward providing the remainder of its applicable information in GIS format, expanding the availability of its products in gridded format (especially for TAFB), and using Internet audio and video podcasts for its hurricane briefings.

While NOAA has made significant strides in operational hurricane forecasting, there are areas that need further advancements. In 2007, NOAA established the Hurricane Forecast Improvement Project (HFIP). This came in response to input from stakeholders and from reports by the National Science Board (NSB), the Office of the Federal Coordinator for Meteorology (OFCM), and NOAA's Science Advisory Board Hurricane Intensity Research Working Group (HIRWG) calling for significant and accelerated improvements in hurricane forecasts. The project is intended to unify hurricane 


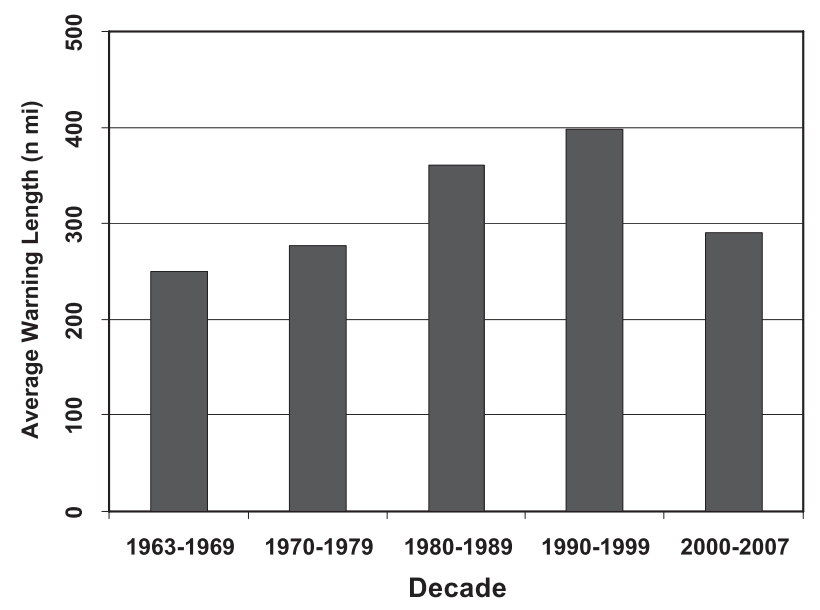

FIG. 14. Average U.S. hurricane warning length by decade.

forecast improvement activities between NOAA, its federal partners, and the external research community.

The HFIP draft 10-yr project plan addresses the highest priority challenges in operational hurricane forecasting: progress in hurricane intensity forecasting, especially rapid intensification; forecast uncertainty; and improved model guidance. The major components of the HFIP plan are 1) improving the Hurricane Forecast System $(\mathrm{HFS})^{5} /$ Global Forecast System (GFS) to reduce error in track and intensity guidance; 2) optimizing observing systems to enhance capabilities for hurricane research, operational modeling, analysis, and forecasting; and 3) expanding and enhancing forecast tools and applications to add value to the output from model guidance and the direct use of observations.

New science and technology will advance operational tropical cyclone forecasting. To achieve NHC's vision of a global community safe from tropical weather threats, however, requires more-an interdisciplinary collaboration to develop and implement long-term strategies and policies minimizing people and property at risk from tropical weather. Solutions will require strong leadership with staying power (e.g., across multiple national administrations) and broad participation to address such sensitive issues as land use, building codes, and evacuation policies and procedures. NHC remains committed in this pursuit to working as a partner with the public, with the private sector, and with others in government in this country and abroad.

\footnotetext{
${ }^{5}$ The HFS is currently the HWRF coupled model and data assimilation system composed of two nests at 27- and 9-km grid spacing using the NMM core, and physics from the GFS and GFDL models.
}

Acknowledgments. The authors thank several colleagues for contributions to this paper: Naomi Surgi helped develop the numerical modeling discussion; Ethan Gibney generated Figs. 1, 8, and 9; Tarah Sharon, Rebecca Waddington, and Joan David helped make Fig. 10; Tim Marchok provided Fig. 13 and supporting data; Mark DeMaria made helpful suggestions to an early draft, and also made available Fig. 14 and supporting data analyzed by Dan Brown; DeMaria and Todd Spindler provided information about NHC's initial Internet presence; Matthew Green improved the description of the HLT; and Alison Krautkramer, Charles Sampson, Ann Schrader, Christopher Lauer, and Jamie Rhome assisted in the development of the ATCF section.

\section{REFERENCES}

Aberson, S. D., 1998: Five-day tropical cyclone track forecasts in the North Atlantic basin. Wea. Forecasting, 13, 1005-1015.

Bender, M. A., I. Ginis, R. Tuleya, B. Thomas, and T. Marchok, 2007: The operational GFDL coupled hurricane-ocean prediction system and summary of its performance. Mon. Wea. Rev., 135, 3965-3989.

Bessho, K., M. DeMaria, and J. A. Knaff, 2006: Tropical cyclone wind retrievals from the Advanced Microwave Sounding Unit: Application to surface wind analysis. J. Appl. Meteor. Climatol., 45, 399-415.

Beven, J. L., and Coauthors, 2008: Atlantic hurricane season of 2005. Mon. Wea. Rev., 136, 1109-1173.

Black, P. B., and C. L. Swift, 1984: Airborne stepped frequency microwave radiometer measurements of rainfall rate and surface wind speed in hurricanes. Preprints, Second Conf. on Radar Meteorology, Zurich, Switzerland, Amer. Meteor. Soc., 433-438.

Blake, E. S., cited 2007: Tropical cyclone report, Hurricane Humberto, 12-14 September 2007. [Available online at http:// www.nhc.noaa.gov/2007atlan.shtml.]

— E. E. Rappaport, and C. W. Landsea, 2007: The deadliest, costliest, and most intense United States tropical cyclones from 1851 to 2006 (and other frequently requested hurricane facts). Tech Memo. NWS TPC-5, NOAA, U.S. Department of Commerce, 43 pp.

Brennan, M. J., and R. D. Knabb, 2007: Operational evaluation of QuikSCAT ocean surface vector winds in tropical cyclones at the Tropical Prediction Center/National Hurricane Center. Preprints, 11th Symp. on Integrated Observing and Assimilation Systems for the Atmosphere, Oceans, and Land Surface (IOAS$A O L S)$, San Antonio, TX, Amer. Meteor. Soc., 10.5. [Available online at http://ams.confex.com/ams/pdfpapers/117225.pdf.]

Brueske, K. F., and C. S. Velden, 2003: Satellite-based tropical cyclone intensity estimation using the NOAA-KLM series Advanced Microwave Sounding Unit (AMSU). Mon. Wea. Rev., 131, 687-697.

Burpee, R. W., J. L. Franklin, S. J. Lord, R. E. Tuleya, and S. D. Aberson, 1996: The impact of Omega dropwindsondes on operational hurricane track forecast models. Bull. Amer. Meteor. Soc., 77, 925-933.

Cooper, C., and R. Block, 2006: Disaster-Hurricane Katrina and the Failure of Homeland Security. Henry Holt, 333 pp.

Crossett, K. M., T. J. Culliton, P. C. Wiley, and T. R. Goodspeed, 2004: Population trends along the coastal United States: 1980 
2008. Coastal Trends Report Services, NOAA/National Ocean Service Management and Budget Office, 54 pp. [Available online at http://www.oceanservice.noaa.gov/programs/mb/pdfs/ coastal_pop_trends_complete.pdf.]

Davis, M. A. S., G. M. Brown, and P. Leftwich, 1984: A tropical cyclone data tape for the eastern and central North Pacific basins, 1949-1983: Contents, limitations, and uses. NOAA Tech. Memo. NWS NHC 22, 21 pp. [Available online at http:// www.nhc.noaa.gov/pdf/NWS-NHC-1988-22.pdf.]

DeMaria, M., 1996: A history of hurricane forecasting for the Atlantic basin, 1920-1995. Historical Essays on Meteorology 1919-1995, J. R. Fleming, Ed., Amer. Meteor. Soc., 263-306.

_- M. Mainelli, L. K. Shay, J. A. Knaff, and J. Kaplan, 2005: Further improvements to the Statistical Hurricane Intensity Prediction Scheme (SHIPS). Wea. Forecasting, 20, 531-543.

— J. J. A. Knaff, and J. Kaplan, 2006: On the decay of tropical cyclone winds crossing narrow landmasses. J. Appl. Meteor. Climatol., 45, 491-499.

Demuth, J. L., M. DeMaria, J. A. Knaff, and T. H. Vonder Haar, 2004: Evaluation of Advanced Microwave Sounding Unit tropical-cyclone intensity and size estimation algorithms. $J$. Appl. Meteor., 43, 282-296.

Dvorak, V. F., 1984: Tropical cyclone intensity analysis using satellite data. NOAA Tech. Rep. NESDIS 11, $47 \mathrm{pp}$.

Elsberry, R. L., 2005: Achievement of USWRP hurricane landfall research goal. Bull. Amer. Meteor. Soc., 86, 643-645.

Fernández-Partagás, J., and H. F. Diaz, 1996: Atlantic hurricanes in the second half of the nineteenth century. Bull. Amer. Meteor. Soc., 77, 2899-2906.

Franklin, J. L., cited 2008: National Hurricane Center forecast verification. [Available online at http://www.nhc.noaa.gov/ verification.]

— M. L. Black, and K. Valde, 2003a: GPS dropwindsonde wind profiles in hurricanes and their operational implications. Wea. Forecasting, 18, 32-44.

—, C. J. McAdie, and M. B. Lawrence, 2003b: Trends in track forecasting for tropical cyclones threatening the United States, 1970-2001. Bull. Amer. Meteor. Soc., 84, 1197-1203.

Goerss, J. S., 2007a: Prediction of consensus tropical cyclone track forecast error. Mon. Wea. Rev., 135, 1985-1993.

, cited 2007b: Prediction of consensus tropical cyclone track forecast error and correctors to improve consensus tropical cyclone tracks. USWRP Joint Hurricane Testbed Final Rep., 18 pp. [Available online at http://www.nhc.noaa.gov/jht/0507reports/final_Goerss_JHT07.pdf.]

Gross, J. M., M. DeMaria, J. A. Knaff, and C. R. Sampson, 2004: A new method for determining tropical cyclone wind forecast probabilities. Preprints, 26th Conf. on Hurricanes and Tropical Meteorology, Miami, FL, Amer. Meteor. Soc., 11A.4. [Available online at http://ams.confex.com/ams/pdfpapers/ 75000.pdf.]

Hawkins, J. D., T. F. Lee, J. Turk, C. Sampson, J. Kent, and K. Richardson, 2001: Real-time Internet distribution of satellite products for tropical cyclone reconnaissance. Bull. Amer. Meteor. Soc., 82, 567-578.

Hebert, P. J., and K. O. Poteat, 1975: A satellite classification technique for subtropical cyclones. NOAA Tech. Memo. NWS SR-83, National Weather Service, Fort Worth, TX, 25 pp.

Hock, T. F., and J. L. Franklin, 1999: The NCAR GPS dropwindsonde. Bull. Amer. Meteor. Soc., 80, 407-420.

Hoffman, R. N., and S. M. Leidner, 2005: An introduction to the near-real-time QuikSCAT data. Wea. Forecasting, 20, 476493.
Janjić, Z. I., J. P. Gerrity Jr., and S. Nickovic, 2001: An alternate approach to nonhydrostatic modeling. Mon. Wea. Rev., 129, $1164-1178$.

Jarvinen, B. R., and C. J. Neumann, 1979: Statistical forecasts of tropical cyclone intensity for the North Atlantic basin. NOAA Tech. Memo. NWS NHC-10, 22 pp.

— , and M. B. Lawrence, 1985: An evaluation of the SLOSH storm-surge model. Bull. Amer. Meteor. Soc., 66, 14081411.

— C. J. Neumann, and M. A. S. Davis, 1984: A tropical cyclone data tape for the North Atlantic basin, 1886-1983: Contents, limitations, and uses. NOAA Tech. Memo. NWS NHC 22, Coral Gables, FL, 21 pp.

Jelesnianski, C. P., J. Chen, and W. A. Shaffer, 1992: SLOSH: Sea, Lake, and Overland Surges from Hurricanes. NOAA Tech. Rep. NWS 48, 71 pp.

Knaff, J. A., M. DeMaria, B. Sampson, and J. M. Gross, 2003: Statistical, 5-day tropical cyclone intensity forecasts derived from climatology and persistence. Wea. Forecasting, 18, 8092.

— C. R. Sampson, M. DeMaria, T. P. Marchok, J. M. Gross, and C. J. McAdie, 2007: Statistical tropical cyclone wind radii prediction using climatology and persistence. Wea. Forecasting, 22, 781-791.

Kurihara, Y., and R. E. Tuleya, 1974: Structure of a tropical cyclone developed in a three-dimensional numerical simulation model. J. Atmos. Sci., 31, 893-919.

— for tracking a small vortex. Mon. Wea. Rev., 108, 1792-1809.

$\longrightarrow$, R. E. Tuleya, and M. A. Bender, 1998: The GFDL Hurricane Prediction System and its performance in the 1995 hurricane season. Mon. Wea. Rev., 126, 1306-1322.

Landsea, C. W., 1993: A climatology of intense (or major) Atlantic hurricanes. Mon. Wea. Rev., 121, 1703-1713.

_ , and Coauthors, 2004a: The Atlantic hurricane database reanalysis project: Documentation for the 1851-1910 alterations and additions to the HURDAT database. Hurricanes and Typhoons: Past, Present and Future, R. J. Murname and K.-B Liu, Eds., Columbia University Press, 177-221.

_ (1992) intensity. Bull. Amer. Meteor. Soc., 85, 1699-1712.

- and Coauthors, 2008: A reanalysis of the 1911-20 Atlantic hurricane database. J. Climate, 21, 2138-2168.

Le Marshall, J., and Coauthors, 2007: The Joint Center for Satellite Data Assimilation. Bull. Amer. Meteor. Soc., 88, 329-340.

Mainelli, M., M. DeMaria, L. K. Shay, and G. Goni, 2008: Application of oceanic heat content estimation to operational forecasting of recent Atlantic category 5 hurricanes. Wea. Forecasting, 23, 3-16.

McAdie, C. J., 2004: Development of a wind radii CLIPER model. Preprints, 26th Conf. on Hurricanes and Tropical Meteorology, Miami, FL, Amer. Meteor. Soc., 5D.7. [Available online at http://ams.confex.com/ams/pdfpapers/75190.pdf.]

Mileti, D. S., 1999: Disasters by Design: A Reassessment of Natural Hazards in the United States. Joseph Henry Press, 351 pp.

Miller, R. J., A. J. Schrader, C. R. Sampson, and T. L. Tsui, 1990: The Automated Tropical Cyclone Forecasting System (ATCF). Wea. Forecasting, 5, 653-660.

NAS, cited 2000: From research to operations in weather satellites and numerical weather prediction: Crossing the Valley of Death. The National Academies Board on Atmospheric Sciences and Climate. [Available online at http://dels.nas.edu/ basc/reportDetail.php?link_id=2199.] 
_- A geospatial framework for the coastal zone: National needs for coastal mapping and charting (2004). The National Academies Ocean Studies Board. [Available online at http:// www.nap.edu/books/0309091764/html.]

Neumann, C. B., 1972: An alternate to the HURRAN (hurricane analog) tropical cyclone forecast system. NOAA Tech. Memo. NWS SR-62, 24 pp.

Neumann, C. J., 1994: An update to the National Hurricane Center "Track Book." Minutes of the 48th Interdepartmental Conf., Miami, FL, NOAA/Office of the Federal Coordinator for Meteorological Services and Supporting Research, A-47A-53.

NWS, cited 2007: NWS directives system. [Available online at http://www.nws.noaa.gov/directives/010/010.htm.]

OFCM, cited 2007: National Hurricane Operations Plan (NHOP). Office of the Federal Coordinator for Meteorological Research. [Available online at http://www.ofcm.gov/nhop/07/ pdf/entire-nhop07.pdf.]

Pasch, R. J., L. A. Avila, and J. L. Guiney, 2001: Atlantic hurricane season of 1998. Mon. Wea. Rev., 129, 3085-3123.

Passi, R. M., 1974: Wind determination using Omega signal. $J$. Appl. Meteor., 13, 934-939.

_ network. J. Atmos. Oceanic Technol., 4, 690-700.

Rappaport, E. N., 2000: Loss of life in the United States associated with recent Atlantic tropical cyclones. Bull. Amer. Meteor. Soc., 81, 2065-2073.

_- and J. Fernandez-Partagas, 1995: The deadliest Atlantic tropical cyclones, 1492-1994. NOAA Tech. Memo. NWS NHC-47, Coral Gables, FL, 41 pp.

Sampson, C. R., and A. J. Schrader, 2000: The Automated Tropical Cyclone Forecasting System (version 3.2). Bull. Amer. Meteor. Soc., 81, 1231-1240.
Schleifstein, M., and J. McQuaid, cited 2002: Washing away. Special report from The Times-Picayune. Part 2: The Big One. [Available online at http://www.nola.com/washingaway.]

Sheets, R. C., 1985: The National Weather Service Hurricane Probability Program. Bull. Amer. Meteor. Soc., 66, 4-13. 1990: The National Hurricane Center-Past, present, and future. Wea. Forecasting, 5, 185-232.

Surgi, N., cited 2007: Advanced hurricane prediction at NCEP's Environmental Model Center: The operational implementation of the HWRF. [Available online at http://www.ofcm. gov/ihc07/linking_file_ihc07.htm.]

Uhlhorn, E. W., and P. G. Black, 2003: Verification of remotely sensed sea surface winds in hurricanes. J. Atmos. Oceanic Technol., 20, 99-116.

$\longrightarrow,-$ J. L. Franklin, M. Goodberlet, J. Carswell, and A. S. Goldstein, 2007: Hurricane surface wind measurements from an operational Stepped Frequency Microwave Radiometer. Mon. Wea. Rev., 135, 1370-1385.

White, S. R., J. D. McFadden, and J. L. Franklin, 1998: Atmospheric observations with the NOAA Gulfstream IV-SP. Preprints, 10th Symp. on Meteorological Observations and Instrumentation, Phoenix, AZ, Amer. Meteor. Soc., 38-41.

Williford, C. E., T. N. Krishnamurti, R. Correa Torres, S. Cocke, Z. Christidis, and T. S. Vijaya Kumar, 2003: Real-time multimodel superensemble forecasts of Atlantic tropical systems of 1999. Mon. Wea. Rev., 131, 1878-1894.

Willoughby, H. E., E. N. Rappaport, and F. D. Marks Jr., 2007: Hurricane forecasting: The state of the art. Nat. Hazards Rev., 8, 45-49.

WMO, 2006: Regional Association IV (North America, Central America and the Caribbean) Hurricane Operational Plan. WMO/TD-No. 494, Tropical Cyclone Programme Rep. TCP$30,98 \mathrm{pp}$. 